\title{
Creative Production and Exchange of Ideas
}

\author{
Iryna Sikora \\ Department of Economics, University of Alicante Madrid, Spain \\ sikora.iryna@gmail.com, isikora@ua.es
}

\begin{abstract}
This paper explores the relationship between individual creative productivity and learning about ideas of others. I report evidence from a two-stage real-effort lab experiment, in which subjects perform ideageneration tasks. In the first stage some subjects observe creative output of other players, while the others not. This design makes possible to assess whether learning ideas of others is an important input for idea generation and quantify its importance. In the second stage, I make ideas costly and study the subjects' willingness to pay for them. I compare the costs of ideas to the expected monetary benefits from increased creative productivity and characterize investment behavior of the subjects. The results show that observing output of others boosts productivity in creative tasks, but only when it shows truly new, previously unknown by the subject items. When ideas of others become costly, I find that the subjects do not act in a profitmaximizing way. To minimize the costs they choose to see the ideas of less creative players, which usually do not contribute many original items. As a result, the participants get less than optimum benefits. This effect is more pronounced for subjects of lower creative ability, more risk-averse or self-confident participants and females. In aggregate, such behavior does not lead to the highest possible level of creative production. These findings make an argument for policies that encourage exchange of information at a workplace (e.g. teamwork, workshops) and at the same time show the need for oversight, central planning of collaborative activities or other actions that may help to creative professionals to invest efficiently, when access to ideas of others is costly.
\end{abstract}

Keywords: Creativity, experiment, exchange of ideas.

\section{Introduction}

The understanding that more interactions between professionals lead to higher productivity has been widely supported by organizations ${ }^{1}$. The belief that being in touch with more people is beneficial for job performance is shaping a new corporate trend. Diverse tools for professional communication emerge and flourish (e.g., webinars, ideas.repec.org, LinkedIn). Firms actively use secondments, regular staff catch-ups, open plan office design and common spaces to foster interaction and exchange of ideas ${ }^{2}$. Modern network literature also lists exchange of ideas among the plausible explanations of higher creative productivity (Ductor et al., 2014). Network analysis of creative professionals in different fields suggest that more productive individuals are at the same time more connected and central in their networks, for instance in academia (Goyal et al., 2006) or management (Burt, 2004 and Cross et al., 2008). However, this evidence is derived from exogenously formed networks and does not imply that connections cause productivity (Manski, 1993; Moffit, 2001). It also could be the case that more productive individuals are also more proactive in reaching other people. Understanding as to whether access to new ideas leads to higher creative productivity is insightful. An answer to this question may serve as an argument for or against teamwork, increasing the level of interactions at the workplace or making privileged information available to a wider public ${ }^{3}$. Furthermore, as in many cases

\footnotetext{
1 "A key purpose of the workplace is for sharing ideas including enhancing your product and service offerings, this won't happen by shutting people away," states Matt Oakley, Chairman of the Research Committee of the British Council for Offices.

2 In addition to exchange of ideas, workplace interactions have many other attributes, which are not considered here. Examples include an opportunity to get helpful feedback, find potential collaborators or simply the motivational impact.

3 The US Patent and Trademark Office publishes every patent application "promptly after the expiration of a period of eighteen months from the earliest filing date for which a benefit is sought under title 35, United States Code" (USPTO, Patent Laws, Regulations, Policies \& Procedures).
} 
interactions imply costs in terms of money or time, examining whether people over- or underspend in this context can advocate or criticize different forms of policies intended to encourage exchange of ideas.

This paper addresses these questions with the help of tools from Production Theory and Experimental Economics for the purpose of this study I narrow the definition of interaction to one of its main attributes observing new ideas - and explore how it is embodied in the creative-process technology. I view idea generation as a production process and ideas of others as an input or production factor. The objective of this paper is to explore the relationship between creative productivity and learning about ideas of others by using the evidence from a two-phase real effort laboratory experiment. First, I study whether observing ideas of others lead to an increase in creative productivity and quantify this effect. Second, I analyze individuals' willingness to pay for ideas when access to them is costly. I check if individuals make economically efficient investment decisions in ideas of others and study whether these decisions depend on creative ability of individuals or their behavioral characteristics as for example attitudes towards risk. In order to answer these questions, I analyze the data from a lab experiment, in which subjects perform the Torrance's idea generation task (Torrance, 1974). In different treatments I vary (i) whether or not players are shown output of other subjects, and (ii) whether participants are shown the output of a randomly assigned peer or are given an opportunity to acquire the output of a peer they choose. I measure creative output as a number of conceptually distinct ideas generated and intensity of the treatment as a number of new ideas observed. By comparing the creative output of players who were shown ideas of others (Treatment group) to those who were not (Control group), I quantify the effect that ideas of others have on creative productivity.

I find that observing new ideas leads to a substantial productivity increase, as our Treatment group produced, on average, $20 \%$ more original ideas than our Control group. However, creative productivity only responds to new, original ideas of others. Output of low creative-ability players, often trivial and not original, is not beneficial for creative productivity. This finding is consistent with multiple creative stimuli mechanism, where a new idea is born as a combination of several existing ones (Nijstad and Stroebe, 2006). If a subject does not observe a new concept, no new combination is produced. In the treatments where ideas are costly the subjects can choose whose creative output to observe. All players are characterized by (i) the number of ideas they have and (ii) the cost that another subject would need to pay in order to see these ideas. The latter cost is set to be an increasing function of a player's output. In the experiment the participants are free to acquire ideas of none, one or more subjects from this menu. I interpret a decision to acquire ideas as an investment decision. Each investment has a fixed cost and an uncertain benefit from new ideas in terms of an increase in creative productivity. I explore the role of own creative ability, behavioral and demographic characteristics for investment behavior. I find that subjects do not act in a profit-maximizing way. They systematically overestimate potential benefits from ideas of low creative ability players. This effect is more pronounced for females, subjects with a higher degree of risk aversion or self-confidence and those of lower creative ability. This evidence warns that endogenously formed interaction patterns do not ensure high returns.

The most creative players are rarely reached and potential benefits from these interactions are not released. Policies that alleviate the costs or externalize choices would be beneficial and desirable for the society. Our first contribution is to consider non-monetary instruments of fostering creativity, ideas of others. The experimental literature on creativity is mainly dedicated to exploring the effectiveness of different forms of monetary incentives to stimulate creative performance (e.g. Eisenberg and Rhoades, 2001; Kachelmeier et al., 2008; Charness and Grieco, 2019; Bradler et al., 2019), and this study broadens the set of available tools. Our second contribution is to provide a numerical assessment of the increase in creative productivity caused by observation of ideas of others. This contributes to sociological work on group brainstorming (Paulus and Yang, 2000; Dugosh et al., 2000; Nijstad et al., 2002). Our third contribution is to estimate the relationships between creative productivity and willingness to acquire ideas of others. To the best of our knowledge, this paper is one of the first attempts to consider the technology of creative process from the point of view of production theory and to evaluate the efficiency of investment decisions in a real-effort creative task. The reminder of the paper is organized as follows. Section 2 summarizes the views on creativity and its measurement, mainly from the fields of Psychology and Sociology, and comments on the existent studies related to creativity, in particular in Economics. Section 3 describes the experimental design. The estimation 
strategy is described in Section 4, followed by Section 5 reporting on results. Finally, Section 6 concludes by listing possible applications of our findings and outlines guidelines for further research.

\section{Literature Review}

Definition and Measurement of Creativity: While it is widely accepted that creative process constitutes a basis for innovation, there is still no universal way of defining what creativity is. Meusburger (2009) reckons that over a hundred different analyses can be found in the literature. Some authors argue creativity is a mind skill, while others consider it a process equipping us to make a new idea. The most common way of defining creativity is the production (or development) of ideas, solutions or products that possess two essential characteristics: novelty (or originality) and appropriateness (or usefulness for a given context) (Stein, 1974; Woodman et al., 1993; Amabile, 1996; Shalley and Perry-Smith, 2001; Mumford, 2003; Byron and Khazanchi, 2012). This definition of creativity is broad enough to accommodate different types or dimensions of creativity phenomena. The majority of creativity classifications can be represented on the convergentdivergent thinking spectrum (Sternberg, 2006; Galenson, 2004; Runco, 2006, 2007). Convergent thinking is essentially the skill or ability to come up with a solution to a well-defined problem, with the unique correct answer, while divergent thinking represents the ability to find versatile solutions to problems with many correct answers. In this way, different types of creativity require specific approaches to measure it, although the majority of proposals provide a combined measure of convergent and divergent thinking (Nielsen et al., 2008). The most common ways of creativity measurement appropriate for being used in the laboratory rely on some type of a creative task ${ }^{4}$.

The tasks are usually tailored to a specific type of creativity that the researchers intend to measure, as they are thought to call for different types of creativity (Stanovich and West, 2000; Kahneman, 2011). In order to measure convergent thinking, closed tasks are used, which call for rational response and contributory creativity. Examples of closed tasks include solving a puzzle (Rutstrom and Williams, 2000; Ariely et al., 2009), finding a way to apply mathematical operations to achieve a given result (Charness and Grieco, 2019). For divergent thinking measurement, open tasks are usually used by the researchers, which call for proactive creativity. Examples of open tasks include thinking of the title for a story (Eisenberg and Rhoades, 2001), developing rebus-puzzles (Kachelmeier et al., 2008), composing a story (Charness and Grieco, 2019), multiple uses task (Bradler et al., 2019). Another important aspect of assessing creativity is the grading procedure after the task is completed. Here, as well, the grading system usually depends on the task and vary a lot across studies. Examples of grading systems include: time to complete the task, whether the task was completed in a given time, subjective grade assigned by an "expert" or by a peer, numerical measures, such as a number of different ideas generated, or a combination of several methods. Traditional creativity measures widely used in social psychology lean toward divergent thinking standardized measurement, and rely on Guilford's intelligence tests $(1950 ; 1967)$ or Torrance test of creative thinking (1974).

Existing Literature on Creativity: Economic literature on creativity is mostly interested in ascertaining what drives creativity by understanding which environments help to maximize creative output. The main stream of academic studies is dedicated to the role of monetary incentives on creative performance. Some studies have found that incentives may be counter-productive for creative performance (Gneezy and Rustichini, 2000; Ariely et al., 2009; Amabile, 1996; Kohn, 1993; Hennessey and Amabile, 1998). At the same time, there are studies that report the opposite, at least for some specific creative tasks. Eisenberg and Rhoades (2001) report rewards leading to higher creative task performance, Nickerson (1999), Collins and Amabile (1999) arrive to similar results. Charness and Grieco (2019) observe better creative output under performance-contingent scheme in comparison to flat incentives in closed creativity tasks but not in open tasks. Also, there are several studies that explore how additional attributes of incentive schemes affect creative output, such as competition and quality or quantity incentives. From point of view of competition, it was shown that creative output improves under more competitive, but not extremely competitive, reward schemes (Bradler et al., 2019; Gross, 2018). As for quantity versus quality considerations, these two

\footnotetext{
${ }^{4}$ Social psychology also uses carefully designed personality tests, which allow to identify personality treats related to creativity or self-reported description of own personality.
} 
attributes of creative output are shown to be positively correlated (Stroebe and Diehl, 1994), and the incentive schemes that reward quantity but not quality leads to the best results in terms of quantity and quality of the creative output, compared to incentivizing just quality or both (Kachelmeier et al., 2008). Another stream of literature is dedicated to individual and group performance in creative tasks.

The evidence on group versus individual performance is mixed. In some settings groups show better creative output (Stroebe and Diehl, 1994; Paulus and Yang, 2000; Dugosh et al., 2000; Nijstad et al., 2002). The mechanism of this effect is that "ideas of others help to retrieve categories of ideas they will increase the diversity of idea production" (Nijstad and Stroebe, 2006). This explanation is consistent with so-called "On one hand, on another hand" effect discussed by social psychologists: when two ideas are combined, a new idea is born. In some other settings, however, individual creative output was superior compared to groups (Treffinger et al., 2006). Free-riding and coordination difficulties in groups are listed as plausible causes of the latter finding. In this way, settings that make it easy to combine the creativity of several individuals but at the same time eliminate inefficiencies of the groups should lead to better creativity outcomes. As for creativity in risky environments, recent research shows that underperforming individuals are willing to take more risk (Gross, 2018), consistent with theoretical predictions on actions associated with higher-variance outcomes. Individuals that are falling behind in a competition are willing to take more risks, as that may increase probability of catching up (Cabral, 2003; Anderson and Cabral, 2007).

\section{Experimental Design}

Experimental Tasks: Departing from an understanding of the creative process as generating new and appropriate ideas, this paper considers creative productivity from the point of view of Production Theory. By combining definitions of productivity (output per unit of input) and creativity (production of new output), creative productivity here is defined as a variety of new outputs produced with homogeneous inputs. Defined this way, creative productivity falls into category of divergent thinking. This implies that the task used for its measurement should involve creation of new output with many possible right answers, that is, an open task. With this in mind, this paper relies on idea-generation tasks, which can measure creative output numerically, as the number of conceptually different ideas generated by an individual. The tasks used in this experiment are borrowed from the Torrance's Test of Creative Thinking (Torrance, 1974). The Torrance's Test of Creative Thinking (TTCT) is a widely used in Psychology, designed to test divergent thinking, as well as broader creativity and problem-solving skills. The validity of this test has been confirmed in a large number of studies (Kim, 2006). This experiment is based on two tasks from TTCT: the graphic task and the unusual uses or verbal task. In the graphic task, participants are given a geometric form, such as a circle or a cross, and asked to sketch as many objects as possible, incorporating this form. In the unusual uses task, the participants are asked to come up with as many as possible unusual uses for an object, such as pillow or brick.

Both tasks are easy to implement in the laboratory, as they are not time consuming and do not require particular skills or background. Also, both tasks capture a central element of applied business innovations: the fact that most successful innovations present a clever application of an existing idea or process in a new context (Bradler et al., 2019). Originally, performance in TTCT tasks is scored on four scales: (i) fluency, or total number of items produced, (ii) flexibility, or the number of different categories of relevant responses, (iii) originality, or statistical rarity of the responses and (iv), elaboration or the amount of detail. For this experiment, the scoring procedure was modified to depend only on the number of valid (e.g. original) answers and does not account for quality or objective originality of ideas once they pass the minimum requirement of being distinct from each other. There are two main reasons for this modification. First, this straightforward numerical measure avoids relying on opinion of "experts" about quality of creative output. Second, it simplifies and speeds up experiment in the lab, as the quantity incentives and scoring procedure are easy to explain to the participants and are easy to implement in real afford tasks, as output measurement takes less time, reducing the waiting time between the end of experiment and payment to participants. Motivated by the fact that quality of ideas goes hand-to-hand with quantity (Christensen et al., 1957; Stroebe and Diehl, 1994; Kachelmeier et al., 2008), I believe that in a properly incentivized idea-generation task, the number of distinct ideas provides a reliable measurement of an individual's overall creativity. 
Graphic Task: In Graphic Task treatments the participants are given a sheet of paper that contains the same repetitive workpiece (a geometric form). Treatment sessions consisted of two phases: Phase 1 (Creative Production) followed by Phase 2 (Investment). Phase 1 was designed to test experimentally whether observing creative output of others helps an individual to come up with more ideas. Phase 2 was aimed at analyzing investment behavior when ideas are costly. The task is to sketch as many conceptually different objects as possible, which would incorporate given geometric elements.

\section{Figure 1: Examples of Creative Exercise: Graphic Task}

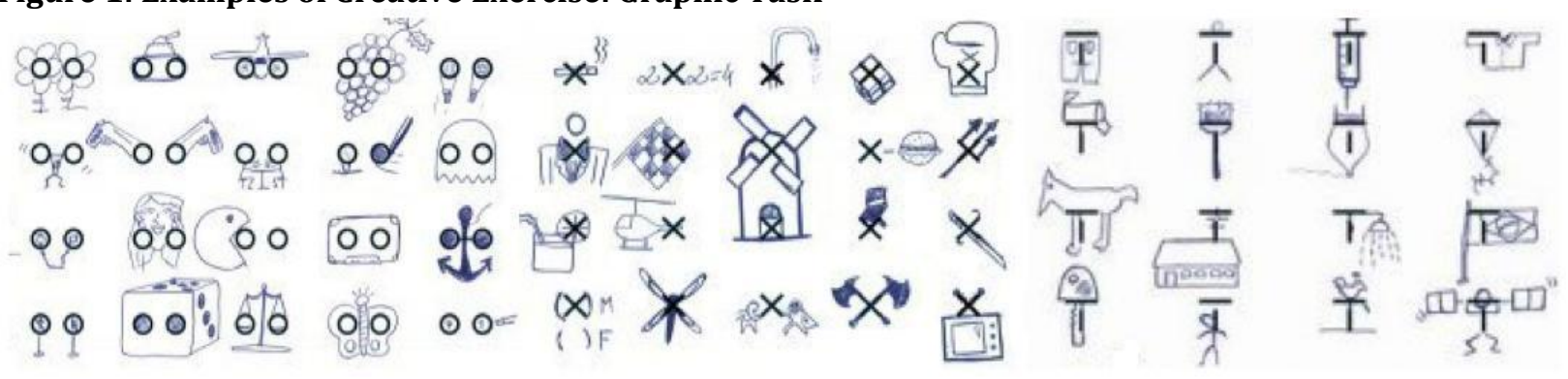

Figure 1 shows several valid examples of creative output corresponding to the different geometrical forms used in the experiment: circles, crosses and Ts. For example, two circles can be used to sketch two flowers, a car or a tire. For measurement purposes, creative output here is defined as the total number of distinct drawings produced within a prescribed time.

Verbal Task: In Verbal Task treatments the participants are shown a picture of a commonly known object and asked to list as many conceptually different alternative uses for that item as they can. Similarly to graphic task, creative output here is measured as a total number of the different alternative uses for the object suggested. The common use, if listed, was not included in the creative output measure.

Table 1: Examples of Creative Exercise: Verbal Task

\begin{tabular}{l|l|l|l}
\hline Pillow & Brick & Pen & \\
\hline & & & \\
\hline $\begin{array}{l}\text { - a Teddy-bear } \\
\text { - to fake pregnancy }\end{array}$ & hold the door & - hair-pin & \\
\hline
\end{tabular}

Table 1 contains several valid alternative uses for the objects used in the experiment: pillow, brick, pen and newspaper.

General Procedures: The experiment was conducted in 15 sessions at the LaTeX laboratory at the University of Alicante. Each session was based on one of the tasks (Graphic or Verbal), with each subject participating only in one session. The sample is based on 181 participants: 52 subjects participated in the Graphic Task ${ }^{5}$ sessions and 129 in Verbal Task ${ }^{6}$ sessions. The subjects were randomly selected from the laboratory's pool of undergraduate students willing to participate in the experiments and then randomly assigned to the Treatment and Control sessions corresponding to each task. In the Treatment sessions, the size of final payment was determined at the end of the experiment by the results of a randomly selected phase. In the Control sessions, participants performed only the first, the Creative Production phase, and were paid

5 There were 30 participants in the Treatment group ( 3 sessions) and 22 participants in the Control group (2 sessions).

${ }^{6}$ There were 60 participants in the Treatment group (4 sessions) and 69 participants in the Control group (6 sessions). 
accordingly. The average payment received in the experiment was 9.5 EUR per hour ${ }^{7}$. At the beginning of each session, a printed copy of the instructions was handed out to every participant and read aloud ${ }^{8}$. Upon completing the experimental tasks all participants were asked to complete a brief questionnaire on their basic socio-economic and demographic background. Table 2 summarizes the general structure of the experiment.

Table 2: Timeline of the Experiment

\begin{tabular}{llll}
\hline Time & Treatment Group & & \multicolumn{1}{c}{ Control Group } \\
\hline & Graphic Task & Verbal Task & Graphic/ Verbal Task \\
stage 1: 00:00-06:00 & TTCT & TTCT & TTCT \\
& Access to ideas of others: & \\
& two relevant ideas & other player's output & \\
stage 2: 06:00-10:00 & TTCT & TTCT & TTCT \\
\hline
\end{tabular}

In each phase the participants had exactly 10 minutes to perform one of the creative tasks. Each phase consisted of two stages: stage 1 lasted 6 minutes followed by stage 2, which lasted 4 minutes. Stage 1 procedures and conditions were identical across all Treatment and Control sessions: participants had to generate as many different ideas as possible in the framework of the creative task. In stage 2 subjects in the Treatment sessions had access to the ideas of others, while subjects in the Control sessions $\operatorname{did}^{\text {not }}{ }^{9}$. The design is absolutely identical for the Treatment and Control session in all respects except for the fact that subjects in Treatment group are shown ideas of others, while subjects in the Control group are not. Thus, any difference in creative output between Control and Treatment groups can only be explained by exposure to the ideas of others. Despite the similar general structure, Graphic and Verbal Tasks bear significant differences with respect to originality of ideas of others.

The ideas shown to the participants in Graphic Task came from an exogenously formed pool of ideas controlled by the experimenter. Graphic Task ensures that each participant observe new ideas in Stage 2. In Verbal Task sessions ideas come from another subject in the lab, e.g. from an endogenously formed pool of ideas. In this case some of these ideas may have coincided with the ones that the recipient has already thought of. Graphic Task design allows studying the pure effect of getting access to new ideas. Verbal Task design makes the number of new ideas available to each subject uncertain. It depends on both, the sender's and recipient's creative abilities, as a more creative sender come up with more original ideas, but at the same time more creative recipients are less likely to receive an item they have not thought of. This setting introduces uncertainty to the payoffs and allows analyzing investment decisions more deeply. Sections 3.2 and 3.3 describe the experimental procedures corresponding to each task in detail.

\section{Graphic Task}

Creative Production (Phase I): After the instructions have been read, the subjects received a sheet of paper with a repetitive geometric form similar to the one depicted in Figure 1. Participants were given 10 minutes to sketch as many different objects incorporating this form as possible. All Graphic Task sessions were paper and pencil. The phase was split into two stages: Stage 1 (first 6 minutes) followed by Stage 2 (last 4 minutes). To distinguish between output produced during the two stages, subjects were asked to change the color of the pen they used while sketching. Control group participants were not given any additional instruction between stages. Treatment group participants were interrupted twice after the end of the first stage: each

7 The average payment was 13.6 EUR per participant in Treatment sessions and 6.7 EUR per participant in Control sessions.

${ }^{8}$ Full instructions for the experiment can be found in the Appendix.

${ }^{9}$ This duration was calibrated to exaust the pool of ideas of participant of above-average creative ability. Six minutes were enough to state all the ideas that the subjects had in almost all the cases, as only two participants reported that they still had not mentioned ideas when the second stage started. 
subject received two envelopes with one relevant drawing each. The first envelope was handed out at the beginning of the 7th minute of the task and the second envelope at the beginning of the 9th minute. The drawings shown to participants were based on the same geometric form that participants had in their task. All examples were taken from the 'bank of ideas' formed as a set of the most uncommon drawings produced in a non-paid preliminary stage by a team of 9 graduate students. To make sure two new drawings were shown, an additional envelope was handed out in case a subject had already sketched a similar object. Subjects were encouraged to develop their own ideas and not to copy examples. Only distinct (from each other and from examples provided) drawings were counted for payment. Control group participants were paid 0.25 EUR per drawing and the Treatment group 0.5 EUR if this phase was chosen for payment.

Investment (Phase II): In Phase 2 acquisition of relevant examples became costly. Only the Treatment group was subject to this phase since these subjects, in contrast to the Control group, may have experienced the benefits of observing new ideas and thus possessed more information to make informed decisions. The experimental procedures had the same structure as Phase 1, but the envelopes were now sold to the subjects willing to pay the price. Prices were randomly assigned across participants and privately communicated to them, ranging from 0.5 EUR to 3 EUR per example. In case this phase was chosen for payment, the participants received 0.5 EUR for each conceptually different drawing minus the total cost of investments they made.

\section{Verbal Task}

Creative Production (Phase I): Similarly to Graphic Task, in Verbal Task some participants were shown the ideas of others, while the others were not. All Verbal Task sessions were computerized ${ }^{10}$. After reading the instructions, the participants saw on their screens a well-known object and were given 10 minutes to type as many unusual uses for this object as they could.

\section{Figure 2: Verbal Task, Stage 1}

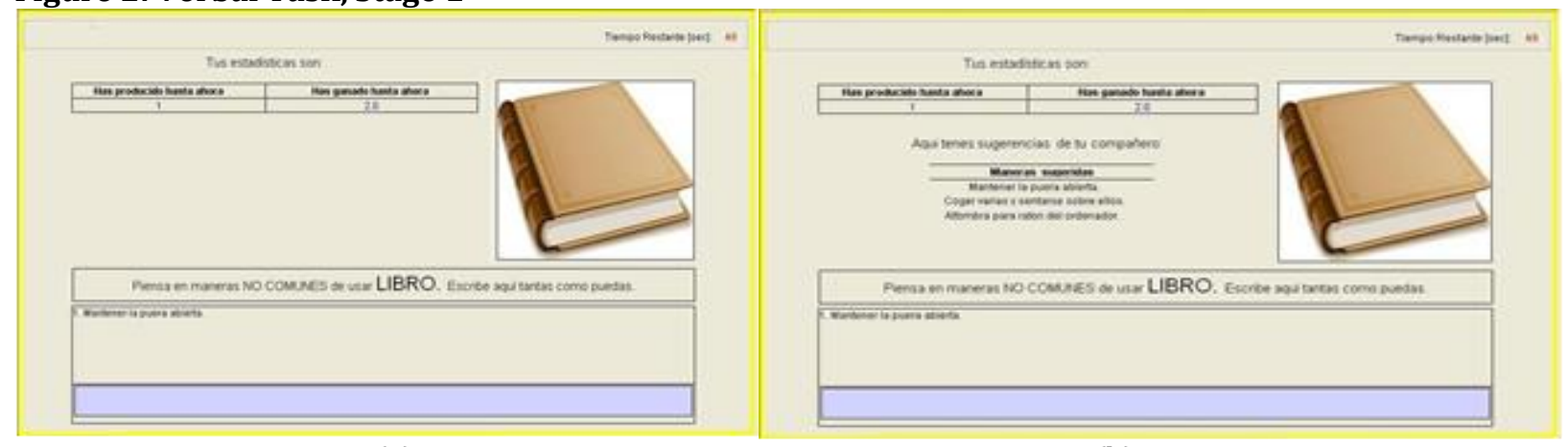

(a)

(b)

As in Graphic Task, Phase 1 consisted of two consecutive stages: Stage 1 (6 minutes) and Stage 2 (4 minutes). Figure 2(a) shows the Stage 1 user interface. Unusual uses suggested by a subject were numerated and shown on the screen together with total number of items and the earnings they would get so far. Figure 2(b) shows the Stage 2 user interface. At minute 6, each subject in the Treatment group was randomly matched to another participant. All the items suggested by her partner during Stage 1 appeared on the screen. The matching was not symmetric, e.g. it is not necessarily the case that two subjects observe the ideas of each other. The Control group participants were not shown any new information and just have 4 additional minutes to perform the same task. The payment scheme was exactly the same as for Graphic Task: the Control group participants received 0.25 EUR for each conceptually different item; The Treatment group participants were paid 0.5 EUR for each unique item if this phase was chosen to be paid. It is not possible to ensure in the computerized that all the ideas observed by the participants are new to them due to technological restrictions. Several people often come up with several similar ideas, particularly at the very beginning of the

${ }^{10}$ The experiment was programmed and conducted using z-Tree software (Fischbacher, 2007). 
phase. Thus, a part of output shown to the subjects sometimes duplicated their own output, in other words, not all ideas were new to the subjects.

Investment (Phase II): As in Graphic Task, Phase 2 introduced the costs of obtaining access to ideas. However, unlike in Graphic Task, subjects could choose their partner. When participants reached minute 6, they were randomly split into groups, each consisting of five people. Each group member had an opportunity to buy access to the Stage 1 output of her group members. I use the Heckman Selection Model (Heckman, 1979) to characterize the partner selection in this experiment. The Heckman two-step procedure allows me to correct for selection bias, which can occur since I only observe the partners of subjects who decided to form connections. If the decision to form connections is not random, a simple OLS analysis of the partner selection would be misleading.

\section{Figure 3: Verbal Task, Phase II}

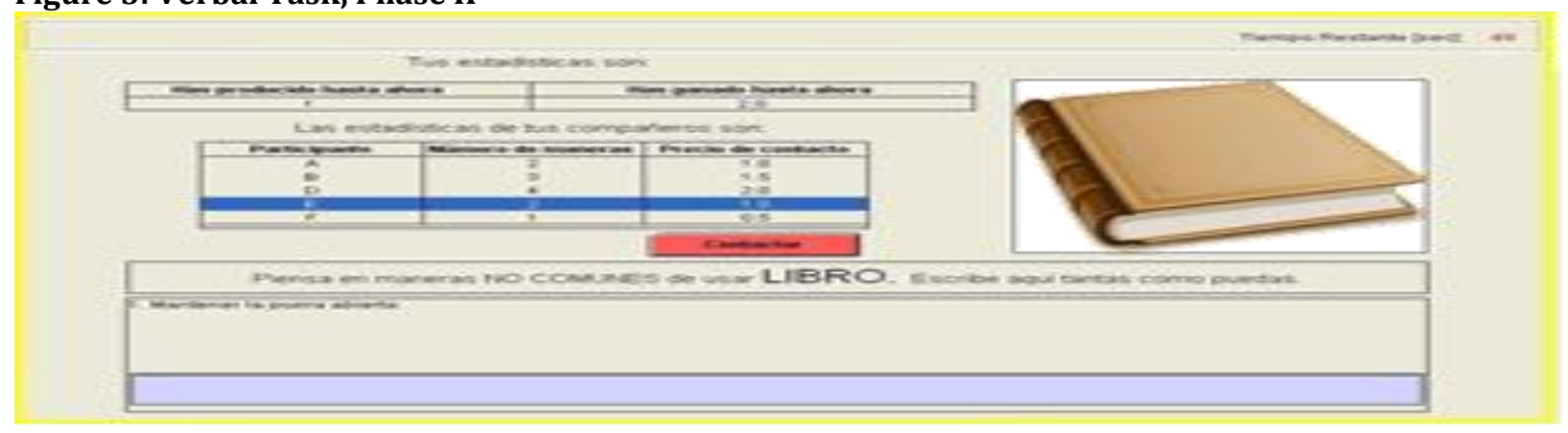

Figure 3 shows the Stage 2 user interface. Each subject was shown a table with a menu of possible contacts available to her. Each potential contact was characterized by a pseudonym, number of items produced in Stage 1 and contact price. To make contacting more creative individuals more expensive, the price was set proportional to the partner's output in Stage 1 (equal to Stage 1 production divided by 10). In these experimental sessions prices ranged from 0.5 EUR to 2.6 EUR per connection. The subjects had to select the corresponding line and press the button "Contact" to see the output of a group member. The participants were free to make one, multiple or no contacts at all. The decision to acquire the output of others could be made at any point in time until the end of Phase 2. In the case that the stage was chosen for payment, the participants were paid 0.5 EUR for each unique item minus the total cost of investment in contacts they had made.

Risk and Self-Assessment: Self-assessment and risk attitudes were elicited from incentivized behavior and all socio-demographic characteristics were taken from the questionnaire and are self-reported. In Verbal Task, all the participants assessed their own creative ability with respect to the performance of others, in order to develop a measure of overconfidence (Hoelzl and Rustichini, 2005). Between Stage 1 and Stage 2 of Phase 1, individuals were asked to guess how many participants in their session had come up with more items than themselves. Quadratic scoring rule was used as an incentive scheme: the participants who have guessed correctly received 1.5 EUR, and the less precise the guess was, the less money was paid. Risk attitudes were elicited with the help of the Hey and Orme (1994) procedure in 24 rounds ${ }^{11}$ once the main experiment was over. In addition to other experimental earnings, the subjects were paid the outcome of one of these 24 rounds selected at random.

\section{Creative Productivity}

This section outlines the estimation strategy I use to quantify the effect of new ideas on creative productivity, using the data form the experiment. I also develop a simple econometric model that allows me to analyze the subjects' investment decisions in ideas of other players. Finally, I also discuss these investment decisions in the context of networks, where each connection is represented by a directed link between these two players.

11 See Appendix for procedures. 
In order to conclude on the importance of new ideas por creative productivity I compare average outputs produced by the subjects in Treatment and Control groups during the last four minutes of each stage. During the first six minutes of the task there was no possibility to access the ideas of others, while during the last four minutes, the treatment group was shown several new ideas, which might constitute an important input for creative production. If a new idea generated by an individual represents a combination of different pieces of already available information, only new pieces of information would stimulate generation of new ideas. Learning an idea, which is not currently in the individual's stock, adds a new element to her information set.

New Ideas and Creative Production: This permits creation of new, unavailable before, combinations of information, which in turn might convert to new ideas in what follows I call these new, potentially beneficial items 'relevant' ideas for a given individual. Note that relevance here is a relative concept, as the same idea may be relevant for one individual and at the same time irrelevant for another. Let $N=\{1 ; 2 ; \ldots ; n\}$ be a set of creative producers, and $i$ is a member of this set. Let producer $i$ be endowed with creative ability $c_{i} \in[0 ; 1)$. This creative ability reflects an average speed of idea generation when $i$ has no access to any inputs. I denote as $y_{i}^{S 2}$ the number of creative items $i$ has produced during the last four minutes (stage 2) of a phase. I model $i$ 's production during the last four minutes of the task as a linear function of her creative ability $c_{i}{ }^{12}$. If $i$ belongs to the treatment group in addition to own creative ability, her production is also a function of the number of relevant items available to her. Let's denote the number of there relevant ideas by $g_{i}$. So, to estimate the relationship between the number of relevant items observed by $i$ and the number of creative items she produces.

I use the following functional specification:

$$
y_{i}^{s 2}=\alpha_{0}+\alpha_{1} c_{i}+d_{i} \times\left(\beta_{0}+\beta_{1} g_{i}\right)+u_{i}
$$

Where $d_{i}$ is a dummy equal to 1 for all $i$ that belong to the Treatment group and equal to 0 for $i$ in the Control group, $u_{i} \sim N\left(0 ; \sigma_{u}\right)$ is an error term, $\alpha_{0}, \alpha_{1}, \beta_{0}$ and $\beta_{1}$ are the parameters to be estimated. Even though true creative ability $c_{i}$ is not observed, I can use the number of items produced by $i$ during the first six minutes of the task, $y_{i}^{S 1}$, as a reliable proxy. At this stage there is no other factor influencing productivity, meaning that the final output must be highly correlated with individual's creative ability. In the described setting, the number of relevant ideas player $i$ observes is the only variable input for the production of ideas. An individual's ability to create $c_{i}$ constitutes an individual-specific production technology. As explained at the beginning of this Section, the number of relevant items, $g_{i}$, is individual-specific. In what follows I explain my approach to its assessment.

Graphic Task: The design of the graphic task is such that the examples are taken from the 'bank of ideas'. It makes sure that each participant in the Treatment Group gets two relevant examples. In this case $g_{i}$ is exogenously set and does not depend on an individual's or partner's creative ability: $g_{i}=g=2$ for any $i$.

Verbal Task: As described in the experimental design, at the beginning of Stage 2 individual $i$ is randomly matched to individual $j$. As the result of this interaction $i$ observes $y_{j}^{S 1}$ items - all $j$ 's output generated during the first six minutes of the task (Stage 1). However, it is not necessarily true that all $y_{j}^{s 1}$ items are relevant to $i$ : so $g_{i} \leq y_{j}^{S 1}$. Under random matching and assumption of finite set of all possible ideas, it must be true that the number of ideas relevant for $i$ is positively related to the size of $j$ 's set of ideas, while negatively related to the size of own idea set. In other words, the probability that a randomly chosen $j$ 's idea is relevant to $i$ increases with the number of ideas $j$ has and decreases with the number of ideas $i$ has. To take into account these considerations I shall approximate the number of relevant ideas $i$ receives from interaction with $j$ with the function increasing in $y_{j}^{S 1}$ and decreasing in $y_{i}^{S 1}$.

$$
g_{i}^{J}=\frac{y_{i}^{S 1}}{y_{j}^{S 1}+y_{i}^{S 1}} \times y_{i}^{S 1}
$$

12 I tested for potential non-linear effects and the results indicate that a linear model fits the data better. 
I choose to use (2) to assess the number of relevant ideas $i$ gets from interaction with $j$ due to its simplicity and intuitively ${ }^{13}$. The identification of (1) is possible due to two-step random assignment: (i) random assignment of the participants to the Treatment or Control group and (ii) random matching between individuals in the verbal task. As long as the creative abilities of the matching partners are uncorrelated, the true causal relationship can be estimated. If I find the estimate $\hat{\beta}_{1}$ to be positive, I would interpret it as a positive effect of observing relevant ideas on own creative productivity. This would mean that there are positive benefits of access to ideas of others on aggregate output. I expect the constant treatment effect $\hat{\beta}_{0}$ to be equal to zero if only relevant ideas are useful for creative production. The opposite would mean that a constant treatment effect exists and it is independent of the number of relevant ideas the players observe.

Investment Decisions: Once the impact of new ideas on creative productivity is estimated, I can draw an inference about the increase in potential productivity that a new idea brings. For any pair of producers $i$ and $j$, it is possible to assess a number of additional items $i$ should expect to produce if she observes $j$ 's items. Denote $\lambda_{i}$ the expected number of new ideas $i$ produces when she observes $j$ 's output. The expected value this connection brings to $i$ can be assessed as:

$$
E\left(\lambda_{i}^{j}\right)=\widehat{\beta}_{0}+\widehat{\beta}_{1} g_{i}^{j}
$$

where $\hat{\beta}_{0}$ and $\hat{\beta}_{1}$ are the $\mathrm{OLS}^{14}$ estimates of equation (1) and $g_{j}^{j}$ is given by (2). Conceptually, $\lambda_{i}$ represents $i^{\prime}$ s opportunity cost of investment in $j$ 's ideas. If $i$ is a payoff-maximize, $\lambda_{i}$ would represent the maximum price she is willing to pay to observe the output of $j$. Let $P_{i}^{j}$ denote the price $i$ must pay to access the ideas of $j$. The net benefit $i$ receives from connection to $j, \pi_{j}^{j}$, is given by the difference between expected output increase and the price:

$$
\pi_{i}^{j}=\widehat{\beta}_{0}+\widehat{\beta}_{1} g_{i}^{j}-P_{i}^{j}
$$

Let $x_{i}$ be a binary variable representing $i$ 's investment decision: $x_{i}=1$ when $i$ decides to acquire someone' ideas in the second stage and $x_{i}=0$ otherwise. An investment is beneficial only when it brings positive net profits. I estimate the following equation to infer if on average the investment decisions in the experiment are beneficial to the participants (rather than loss-making):

$$
x_{i}=\gamma_{0}+\gamma_{1} \lambda_{i}^{j}+\gamma_{2} P_{i}^{j}+v_{i}
$$

Where $v_{i} \sim N\left(0 ; \sigma_{v}\right)$ is an error term, $\gamma_{0}, \gamma_{1}$ and $\gamma_{2}$ are the parameters to be estimated. If participants make profit-maximizing investments, the costs and benefits of the connections would have the same weight for the investment decisions, and I should observe $\hat{\gamma}_{1}=-\hat{\gamma}_{2}$. If, instead, $\hat{\gamma}_{1}>-\hat{\gamma}_{2}$, data would indicate that expected benefits, on average, outweigh price effect in the investment decision process, and the producers are willing to carry out loss-making investments. Regarding the constant term, I should find $\hat{\gamma}_{0}=0$ if investment decisions are not systematically influenced by factors other than costs and benefits of connections. Instead, for example, if subjects derive some utility from interactions, I may observe our constant term being positive ${ }^{15}$.

Partner Selection: When, as in our verbal task, a producer has more than one investment possibility, the fact that an investment is not loss-making does not necessarily imply it is a net-benefit maximizing decision. Imagine producer $i$ can choose between two potential connections (partners): producer $j$ (with $y_{j}^{S 1}$ items) and producer $k$ (with $y_{k}{ }^{S 1}$ items). According to the experimental design, the price associated to each of these connections is proportional to the number of items a partner has:

$$
P^{j}=\alpha y_{j}^{S 1}, P^{k}=\alpha y_{k}^{S 1}
$$

${ }^{13}$ (i) The probability of relevance approaches 1 as $y_{j}^{S 1}$ goes to infinity or $y_{i}^{S 1}=0$; (ii) it is equal to zero when $y_{j}^{S 1}=0$ or $y_{i}^{S 1}$ approaches infinity.

14 Estimating (1) with Tobit gives identical to OLS results. Although theoretically bounded below zero, in practice the dependent variable is equal to zero in less than $1 \%$ of the cases.

${ }^{15}$ Note that if the constant is zero, the degree of risk aversion should not influence investment decisions. Any concave utility function is maximized when expected net benefits from investment are maximized. 
Where $\alpha \in(0 ; 1)$ is an exogenously set positive coefficient if $y_{j}^{S 1} \neq y_{k}{ }^{S 1}$, one of the producers will be expected to bring higher net benefits to $i$. A profit-maximizing producer $i$ would choose to acquire output of $j$ if the connection to $j$ results in higher expected profits compared to $k$ :

$$
\begin{gathered}
\widehat{\beta}_{1}\left(q_{i}^{j}-q_{i}^{k}\right)>P_{i}-P_{k} \\
\widehat{\beta}_{0}+\widehat{\beta}_{1} g_{i}^{j}-P^{j}>0
\end{gathered}
$$

Having the estimate $\hat{\beta}_{1}$ from (1) is sufficient for determining a partner (group member) connection that maximizes i's expected benefits (or minimizes her losses). In what follows I refer to such profit-maximizing connection as i's best partner. As explained earlier in this Section, $i$ should form a connection only if she expects to receive positive net benefits from it. Since the best partner brings the highest expected profits, a profit-maximizing $i$ will always chose her best partner among other available connections. Participants who expect to make losses from connection to their best partner should decide not to invest at all. This leads to the selection rule based on the best partner's profitability:

$$
x_{i}= \begin{cases}1 & \text { if } \widehat{\beta}_{0}+\widehat{\beta}_{1} g_{i}^{B P}-P_{i}^{B P} \geq 0 \\ 0 & \text { if } \widehat{\beta}_{0}+\widehat{\beta}_{1} g_{i}^{B P}-P_{i}^{B P}<0\end{cases}
$$

Where $g_{i}^{B P}$ and $P_{i}^{B P}$ are the number or reievant items anu tne connection price for $i$ 's best partner correspondingly. When investment occurs $\left(x_{i}=1\right)$ I observe partner's creative output $y_{j}^{S 1}$ and can assess the number of relevant ideas $i$ observes $g_{i}$. I use the following model to check whether producers indeed chose their best partners:

$$
g_{i}^{j}=\delta_{0}+\delta_{1} g_{i}^{B P}+\theta X_{i}+w_{i}
$$

Where $g_{i}{ }^{P P}$ is the number of relevant ideas $i^{\prime}$ s best partner has, $X_{i}=\left(X^{1} ; \ldots ; X^{n}\right)$ is a vector of $i^{\prime}$ s individual characteristics, $w_{i} \sim N\left(0 ; \sigma_{w}\right)$ is an error term, $\delta_{0}, \delta_{1}$ and $\theta=\left(\theta^{1} ; \ldots ; \theta^{n}\right)$ are the parameters to be estimated. $\delta_{1}$ indicates the degree of similarity between best and chosen partner. $\theta=\left(\theta^{1} ; \ldots ; \theta^{n}\right)$ is a vector of parameters that characterize the importance of individual characteristics for the partner choice. If the participants make profit-maximizing partner choice I should observe connection to the best partner $\left(\hat{\delta}_{1}=1\right.$ and $\left.\hat{\delta}_{0}=0\right)$ and no effect of individual characteristics on the choice $\left(\hat{\delta}_{0}=0\right)$. By examining vector $\theta$ I will be able to highlight individual-specific factors that matter for connection choice. Vector $X_{i}$ is composed by behavioral (risk attitude, overconfidence) and demographic characteristics (gender, GPA, etc.) measured in the experiment or taken from questionnaire responses.

\section{Results}

In this section I report the estimation results. First, I report average treatment effects in Phase I and conclude on the importance of new ideas for creative productivity. Second, I use these estimations to analyze the investment decisions that the participants made in Phase II. The participants were randomly assigned to a Treatment or a Control session and, as expected, all observable demographic characteristics are similar across treatments: around $50 \%$ of the participants are females, the average age is 22.5 years old and the average GPA is around 66\% in both groups. Average levels of creative ability measured as a total number of distinct items produced in Stage 1 are also similar across groups and sessions. There are significant differences in creative output between the tasks: participants produced 10.5 items on average in the graphic task, while the average production was 9.4 items in verbal task. I control for this difference in our estimations. The absence of significant differences ex-ante between Control and Treatment groups should imply that any differences in the output produced during the last 4 minutes is due to the unique variable attribute of the experimental design, access to the ideas of others.

Phase 1-Creative Production: In both experimental tasks experimental design provides identical conditions for the Control and Treatment group participants during the first six minutes of the task. I use creative output produced at this stage, $y_{i}^{S 1}$ as a proxy for $i$ 's creative ability. In the second stage (last 4 minutes) there is just one difference between the treatments: the Control group participants did not have access ideas of others, while the Treatment group participants did. If observing creative output helps to generate more ideas, I should find higher levels of output $y_{i}^{S 2}$ in treatment with access to the ideas of others. Figure 4 shows our aggregate results graphically for each of the two experimental tasks. 


\section{Figure 4: Treatment Effects}

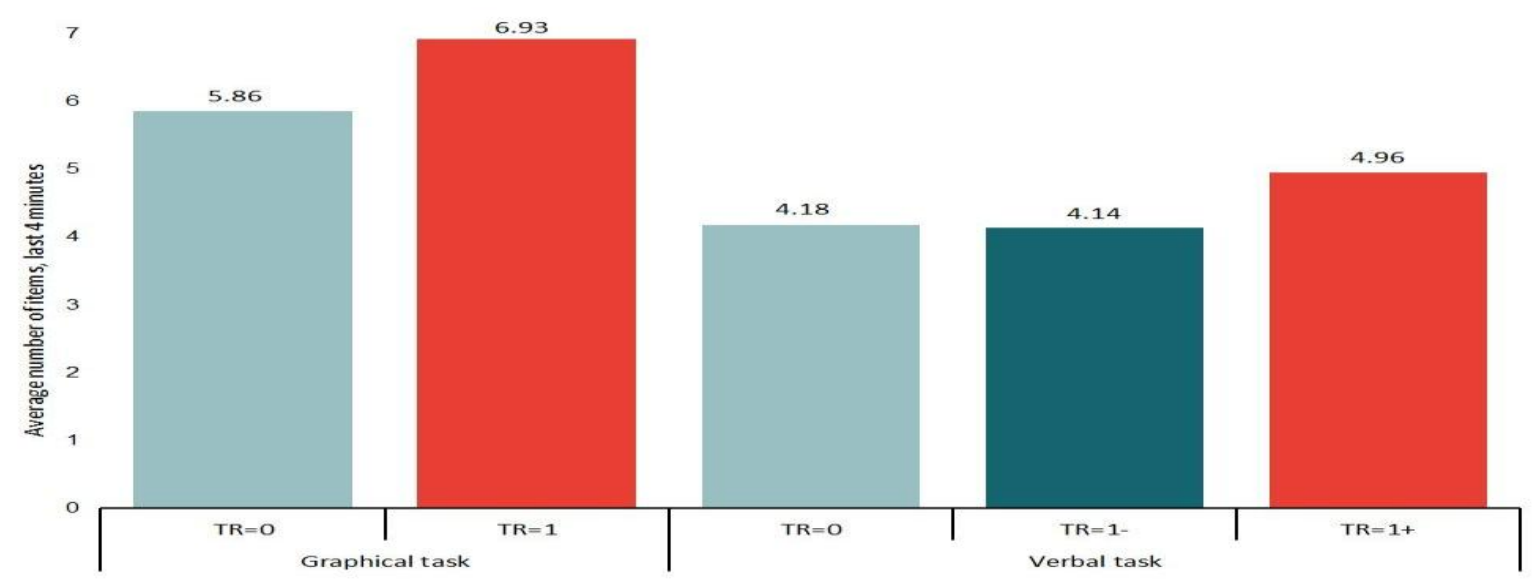

On average, Treatment group ( $\mathrm{TR}=1$ ) produced more creative items during the second stage of the task than the control group ( $\mathrm{TR}=0$ ). In the Graphic task sessions the participants who observed two relevant drawings produced on average 1.07 items more than the Control group participants (one-sided t-test, p-value 0.06). In relative terms, this result translates to a $20 \%$ increase in creative productivity. Regarding the Verbal sessions, a simple comparison between treatments might be misleading. The experimental design of the verbal sessions does not ensure a particular number of new items. In this way, being assigned to the Treatment group does not necessarily imply access to new ideas. With the aim of a simple comparison, I divide Treatment group participants who performed Verbal task into two sub-groups. The first sub-group (TR=1-) includes those participants whose randomly selected connection is a subject of lower creative ability than a median participant, in other words, the number of ideas that these participants observe is less than the median number of items produced in the first stage of the task. The second group (TR=1+) comprises the individuals who observed output of upper-50\% creative individuals. If the ideas that are not new to a subject do not help to generate more creative items, I should expect to find higher production levels for the connections to high-creative ability players (as in $\mathrm{TR}=1+$ ) compared to connections to low-ability players (TR=1-) or no connections at all (TR=0). Indeed, as Figure 4 shows, those connected to lower-than-median participants did not produce more items than Control group participants. Observing ideas of more creative than median participants $(\mathrm{TR}=1+)$ resulted on average in 0.78 extra items produced during the last four minutes of the creative task (one-sided t-test, p-value 0.07 ).

This difference implies a 19\% increase in creative productivity for those who observed items of subjects with upper-tan-median creative ability. These findings are in line with the hypothesis that repetitive ideas are not useful. Only those who had access to a greater number of ideas were more likely to observe new ones and as a result could produce more of their own output. Although these aggregate results are intuitive and easy to interpret, note that the creative output depends not only on the ideas of others, but also on the participants' own creative ability. Controlling for it helps to obtain cleaner and more precise results especially if (as I assume in Section 4) the number of extra items produced is a function of the number of new ideas observed. More creative individuals are less likely to be connected to someone who could ensure many new ideas and their impact could be underestimated in aggregate comparison. I estimate average treatment effects controlling for creative ability to take this consideration into account. In what follows I summarize the results of our OLS estimation. Table 3 contains the results of OLS estimation of creative production function given by (1):

$$
y_{i}^{52}=\alpha_{0}+\alpha_{1} c_{i}+d_{i} \times\left(\beta_{0}+\beta_{1} g_{i}\right)+u_{i}
$$

The first column reports the estimation results based on the data from Graphic Task, the second column only on data from Verbal Task, and the third column uses pooled data from both tasks. For a pooled estimation, I control for potential differences between the tasks by introducing a dummy for Graphic task, GR.

(6) $y_{i}^{P 2}=\alpha_{0}+\alpha_{1} y_{i}^{S 1}+d_{i} \times\left(\beta_{0}+\beta_{1} g_{i}\right)+G R_{i}+G R_{i} \times \alpha_{2} y_{i}^{S 1}+d_{i} \times G R_{i} \times \beta_{1} g_{i}+u_{i}$

This equation does not contain the intersection term between GR and treatment dummy as it is perfectly correlated with $g_{i} \times G R_{i} \times g_{i}$, when $g_{i}$ is constant across individuals as was the case. 
Table 3: Average Treatment Effects

Dependent Variable - Number of Items Produced During the Last 4 Minutes

\begin{tabular}{|c|c|c|c|}
\hline & Graphic & Verbal & Pooled \\
\hline \multirow[t]{2}{*}{ Creative ability (proxy) } & $0.446^{* * *}$ & $0.378^{* * *}$ & $0.378^{* * *}$ \\
\hline & $(0.10)$ & $(0.049)$ & $(0.052)$ \\
\hline \multicolumn{2}{|l|}{ Creative ability task A dummy } & & $\begin{array}{l}0.678 \\
(0.104)\end{array}$ \\
\hline \multirow[t]{2}{*}{ Treatment dummy } & & -1.049 & -1.049 \\
\hline & & $(0.692)$ & $(0.74)$ \\
\hline \multirow[t]{2}{*}{ Relevant items observed (expected) } & $0.596^{* *}$ & $0.356^{* * *}$ & $0.356^{* * *}$ \\
\hline & $(0.298)$ & $(0.128)$ & $(0.137)$ \\
\hline Relevant items task A dummy & & & $\begin{array}{l}0.765^{* *} \\
(0.376)\end{array}$ \\
\hline \multirow[t]{2}{*}{ Constant } & 1.056 & 0.613 & 0.613 \\
\hline & $(1.164)$ & $(0.489)$ & $(0.523)$ \\
\hline \multicolumn{2}{|l|}{ Constant task A dummy } & & $\begin{array}{l}0.444 \\
(1.171)\end{array}$ \\
\hline
\end{tabular}

Standard errors in parentheses: * significant at $10 \%,{ }^{* *}$ at $5 \%,{ }^{* * *}$ at $1 \%$

As Table 3 shows, own creative ability is strongly correlated with creative output in Phase 2. On average, an additional creative item produced in the first stage translates to an increase in Phase 2 production by 0.3780.446 items. The constant term is not statistically significant, which means that if access to the ideas of others is absent, Stage 2 production is proportional to Stage 1 output. This supports validity of using Stage 1 output as a proxy for creative ability. According to the estimation results, being shown ideas of others has a strong positive effect on future creative production in both creative tasks. On average, observing one relevant example leads to an increase in creative output of 0.6 items or $10 \%$ in case of Graphic Task and by 0.35 items or $8.5 \%$ for Verbal Task. In aggregate terms, the estimated increase in creative production is 1.1 items (or 20\%) in Graphic Task and 5.1 relevant items (or 43\%) in Verbal Task. The latter numbers are calculated for average ability individuals. These results provide a strong evidence in favor of the positive effects the ideas of others have on creative production and are consistent with the stream of literature that find positive effects of group creativity versus individual creativity (Stroebe and Diehl, 1994; Paulus and Yang, 2000; Dugosh et al., 2000; Nijstad et al., 2002). Indeed access to ideas of others allows combining the creativity of several individuals but does not create inefficiencies of the groups in terms of coordination or free riding. The next section investigates whether the individuals demonstrate awareness of these potential benefits by making beneficial investment decisions when given the opportunity to acquire access to the output of others.

\section{Phase 2 - Investment}

Decision to Invest: This section analyses the investment decisions of the subjects. Following the discussion of Section 4, in order to conclude whether an investment decision is beneficial I compare expected benefits from investment in acquisition of ideas to the cost of that investment. The benefits are defined as the monetary equivalent of the expected increase in creative output due to new ideas (opportunity costs of investment) and the costs of an investment are given exogenously. For Verbal sessions, there is more than one potential partner and they differ in terms of connection costs as well as in terms of expected new items. Although I observe investment decisions, I do not possess the information on the exact decision-making process. Note that higher creative ability of a partner implies higher expected benefits, but also higher connection costs at the same time. The group member with maximum creative ability is not guaranteed to be the best choice of everyone, as there could be another group member, connection to whom is predicted to result in higher net benefits. For simplicity of analysis, I analyze investment decision from the point of view of 'the best partner rule'. The best partner is a connection that brings the highest expected net benefit. 
A profit-maximizing investor should invest in the connection to her best partner when this expected net benefit is positive and not to invest when negative. To calculate ex-ante opportunity costs for each subject, I first calculate the expected benefits of all connections available to her using the estimates reported in Table 4. Then I compare each expected benefit to the cost of connection specified by the experimental design. In this way I identify the best partner for each subject in the sample. The opportunity costs of investment are the expected benefits associated to the connection to the best partner, the costs are the costs of connection to her. I use (3) to assess to what extend the participants' actual investment decisions are beneficial:

$$
x_{i}=\gamma_{0}+\gamma_{1} \lambda_{i}^{j}+\gamma_{2} P_{i}^{j}+v_{i}
$$

Where $x_{i}$ is equal to 1 when $i$ decides to invest and to 0 otherwise, $\lambda j_{i}$ represents the opportunity costs of investment (in Graphic task) or connecting to the best partner (in Verbal task), $P_{i}^{j}$ is the investment cost. Equality of $\gamma_{1}$ and $\gamma_{2}$ would be an evidence of balanced, profit-maximizing investment decision. The results are presented in Table 4. The first column reports probit estimates of (3) suggesting that higher opportunity costs are associated with a higher probability of investing, and higher connection prices are associated with lower probability of investment. Only the contact price coefficient is significantly different from zero, but the hypothesis regarding the equality the effects and efficiency of investment decisions is not rejected. The second column of Table 4 explores to what extend creative ability determines investment decision. If more productive individuals choose to acquire more ideas, I should observe a positive relationship between creative ability and investment dummy. But as the estimation results suggest, creative ability does have an impact neither on the decision to invest nor on the coefficients of opportunity costs and price. This evidence is in contrast with the hypothesis that higher productivity leads to more interactions. Neither this evidence supports the theoretical prediction on more risky behavior that laggards exhibit in their attempts to catch up (Cabral, 2003; Anderson and Cabral, 2007).

Table 4: Marginal Effects for Investment Decisions, Probit Dependent Variable - Decision to Invest at Least Once

\begin{tabular}{lllll}
\hline & & $\mathbf{( 1 )}$ & $\mathbf{( 2 )}$ \\
& Probit Regr. & Marginal Effects & Probit Regr. & Marginal Effects \\
\hline Opportunity costs & 0.414 & 0.160 & 0.451 & 0.174 \\
(estimated) & $(0.356)$ & $(0.137)$ & $(0.360)$ & $(0.138)$ \\
Price of contact & $-0.537^{* *}$ & $-0.207^{* *}$ & $-0.549^{* *}$ & $-0.212^{* *}$ \\
& $(0.23)$ & $(0.087)$ & $(0.233)$ & $(0.089)$ \\
Creative ability & & & 0.022 & 0.008 \\
& & & $(0.032)$ & $(0.012)$ \\
\hline
\end{tabular}

Standard errors in parentheses: ${ }^{*}$ significant at $10 \%,{ }^{* *}$ at $5 \%,{ }^{* * *}$ at $1 \%$. The next section investigates what other factors other than cost-benefit weighting influence investment decisions in our creative environment.

Choice of a Partner: Verbal session design is based on an environment, which allows me to analyze investment decisions more deeply. Each single investment decision can be partitioned into two sub-decisions: (i) invest or not to invest, and if yes, (ii) whom to choose as a partner. The estimates in Table 4 demonstrate that participants' investment decisions are consistent with the behaviour of a profit-maximizing individual and the potential benefits are on average well calibrated. This section analyses the second part of the investment decision. As I illustrate in Section 4, a profit-maximizing investor should follow the best partner rule. This rule states that if the maximum attainable net benefit is positive, the subject should invest in connection to the individual who is associated to this highest benefit. If, in the opposite case, the highest attainable net benefit is negative, the subject is better off not investing at all and should not form any connections. In what follows, I analyze the relationship between the expected number of relevant items that the best and actually chosen partners have. I do not observe partners for the participants who decided not to invest at all. To control for the link-forming decision, I use the Heckman two-step procedure, where in the first step individuals assess the profitability of investing in a connection to their best partner available, and the second step is actual partner choice. The selection equation is given by (4) and the partner choice by (5). The first-step estimates (selection equation) are reported in Table 4 and are in line with profit-maximizing investment decisions. 
Table 5 reports the estimates of six different specifications for second step, partner selection. The first column of Table 5 shows the basic specification: the dependent variable is the expected number of relevant items a subject' partner has and the independent variable is the expected number of items the subject' best partner has. These estimation results show the absence of any significant relationship between the two. On average, the selected partner's profile does not coincide with the choice that maximizes expected net benefits. Choice of the partner is not a simple decision to be made ex-ante. Before the partner's output is revealed to a participant, in other words, before the decision is made, the number of relevant items remains uncertain. This in turn introduces uncertainty in future benefits and makes investment decision risky. Thus, investment decisions in this environment (as any other decision under risk or uncertainty) might be affected by subjects' risk attitudes or/and other individual characteristics. Columns 2-6 of Table 5 report the estimates of five alternative model specifications. In addition to the best partner items, these specifications include various individual characteristics that may have an effect on the partner's profile. These characteristics include risk attitudes, creative ability, self-assessment of own creative ability, gender, age, GPA and other demographic variables. These connections can be interpreted as unproductive: they are unlikely to bring new ideas but are still costly to participants as Figure 4 shows.

Table 5: Heckman Maximum Likelihood Estimations Dependent Variable - Expected Number of Relevant Items

\begin{tabular}{|c|c|c|c|c|c|c|}
\hline Opportunity osts & 0.521 & $1.081^{* * *}$ & $1.071^{* * *}$ & $1.134^{* * *}$ & $1.127^{* * *}$ & $1.165^{* * *}$ \\
\hline & $(0.39)$ & $(0.39)$ & $(0.39)$ & $(0.38)$ & $(0.38)$ & $(0.37)$ \\
\hline \multirow[t]{2}{*}{ Price of connection } & $-0.528^{* *}$ & $-0.754^{* *}$ & $-0.766^{* *}$ & $-0.760^{* *}$ & $-0.759^{* *}$ & $-0.749^{* *}$ \\
\hline & $(0.21)$ & $(0.35)$ & $(0.36)$ & $(0.33)$ & $(0.33)$ & $(0.33)$ \\
\hline \multirow{2}{*}{ New items (best partner) } & 0.104 & -0.096 & -0.12 & -0.059 & -0.023 & -0.137 \\
\hline & $(0.12)$ & $(0.14)$ & $(0.14)$ & $(0.12)$ & $(0.12)$ & $(0.15)$ \\
\hline \multirow[t]{2}{*}{ Risk parameter } & & $4.917^{*}$ & $5.134^{* *}$ & $7.019^{* * *}$ & $7.308^{* * *}$ & $8.993^{* * *}$ \\
\hline & & $(2.53)$ & $(2.44)$ & $(2.29)$ & $(2.18)$ & $(2.43)$ \\
\hline \multirow[t]{2}{*}{ Perceived ranking } & & & $-5.949 *$ & $-6.063^{*}$ & $-5.382 *$ & $-7.723^{* *}$ \\
\hline & & & $(3.45)$ & $(3.15)$ & $(3.02)$ & $(3.67)$ \\
\hline \multirow[t]{2}{*}{ Creative ability } & & & & $0.468^{* *}$ & $0.526^{* * *}$ & $0.568^{* * *}$ \\
\hline & & & & $(0.19)$ & $(0.18)$ & $(0.19)$ \\
\hline \multirow[t]{2}{*}{ Female } & & & & & $-1.828^{*}$ & $-2.409 * *$ \\
\hline & & & & & $(1.05)$ & (1.11) \\
\hline \multirow[t]{2}{*}{ GPA } & & & & & & 0.127 \\
\hline & & & & & & $(0.09)$ \\
\hline \multirow[t]{2}{*}{ 2D:4D ratio } & & & & & & -16.69 \\
\hline & & & & & & $(20.31)$ \\
\hline \multirow[t]{2}{*}{ Left-handed } & & & & & & -1.70 \\
\hline & & & & & & $(1.95)$ \\
\hline \multirow[t]{2}{*}{ CRT } & & & & & & 0.356 \\
\hline & & & & & & $(0.91)$ \\
\hline
\end{tabular}

Standard errors in parentheses: ${ }^{*}$ significant at $10 \%,{ }^{* *}$ at $5 \%,{ }^{* *}$ at $1 \%$.

The choice of partner is to a great extend explained by an individual's risk attitudes ${ }^{16}$, gender, creative ability and confidence in own creative ability ${ }^{17}$. More risk-neutral subjects usually aim for more creative partners and a 0.1 change in risk parameter toward risk-neutrality imply from 5 to 9 more expected new items

${ }^{16}$ See Appendix for elicitation and estimation. Risk parameter is equal to 1 for risk-neutral individuals and 0 for completely risk-averse.

${ }^{17}$ Self reported percentile according to creative ability. 
depending on specification. The individuals with higher creative ability also opt for connections with a higher expected number of new items and an additional point of creativity is associated with approximately 0.5 additional new items. The subjects with higher self-assessed position in creative ranking, in contrast, aim for less creative partners, where a $10 \%$ increase in self-perceived ranking lowers the expected number of related items by $0.6-0.8$. Furthermore, females chose lower quality partners; their partners are expected to ensure 1.8-2.4 new items less than those chosen by males. However, this result is just marginally significant. Although controlling for other variables such as being left-handed, 2D:4D ratio or GPA and the results of cognitive reflection test adds explicative power to the estimation, these variables do not have a significant effect on the partner chosen. The overconfidence effect could be explained by a desire for superiority, creative ability effect, as possible higher self-awareness due to a deeper experience and risk aversion effect as a desire to avoid higher costs. However, these are only possibilities, as I am not aware of any theory that would embrace all these findings. In his study the participants in competitive treatments (with riskier rewards) produced better creative output (minimizing the risks of not being rewarded). The results of this paper also indicate that more risk a-verse participants act in risk minimizing way by selecting partners that maximize the expected number of new items.

Networks: This section considers the investment behaviour in the context of networks. Figure 5 depicts all the networks formed in the Verbal sessions of the experiment (solid lines). Each node represents an individual, the number next to the node corresponds to their creative ability (e.g. the number of items generated during the first 6 minutes of the creative task) and each arrow between two nodes corresponds to the connections formed by an initiating node to the node of destination. Each network consists of five nodes located in descending order of creative ability from top to the bottom: the node corresponding to the maximum creative ability in a given group is always shown on the top, and the minimum at the bottom. In total, 31 links were formed in 4 sessions. 28 out of 60 participants have decided to form connections: 3 individuals have formed two links, and the remaining 25 one link each. From the other side, 23 individuals were contacted in total, among them 16 were contacted once, 6 were contacted twice and one participant was contacted three times. The findings on importance of attitudes towards risk for investment behavior are in line with the literature on choices under uncertainty, which were not studied much in the context of creativity. Also, these results are in line with conclusions of Gross (2018) on risk minimization in creative contexts. Following the discussion in Section 4, all profit-maximizing links should connect a subject with her best partner. Optimal connections were derived as the connections that give maximum nonnegative expected profit to the participants.

If neither of the available partners gives positive profits, no connections should be formed, and if several of them are expected to bring positive profit, the one corresponding to maximum profit should be optimally chosen. Figure 5 depicts the best partner connections with dashed lines. If there are no dashed lines in the graph, no links should be formed. Only one link was made according to the best partner rule (Session 3, from 10 to 18 ) and a further 30 should not have been formed according to the optimal decision rule. Moreover, although for the majority of participants their predicted best partners are of higher than own creative ability only 11 out of 31 links were made to the people of higher creative ability. The participants of maximum creative ability in the group would be an exception, as the only choice available to them is to connect to someone with a lower creative ability than their own. A total of 8 out of 20 links to nodes of lower-than-own creative ability were formed by maximum ability individuals. However, neither of these links was made to a second-best node, but to substantially lower nodes instead. As the Figure 5 shows, actual connection behaviour in the experiment is at odds with the profit-maximizing strategy. As a rule, the links formed to lower than optimal creative ability individuals result in losses in actual or potential profits from forming links. The explanation to this phenomenon is that, as discussed earlier, the connection behaviour is determined by risk attitudes, own creative ability and other individual characteristics, and does not reflect the best possible connection that could have been made in a given network. 


\section{Figure 5: Real and Profit-Maximizing Networks}

Session 1
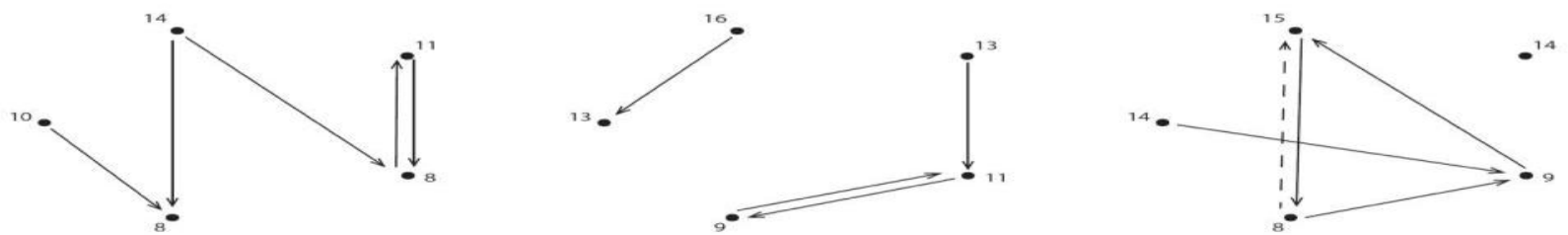

Session 2
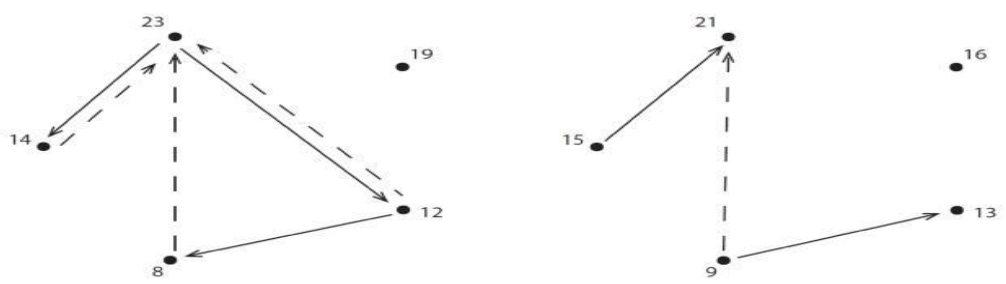

Session 3
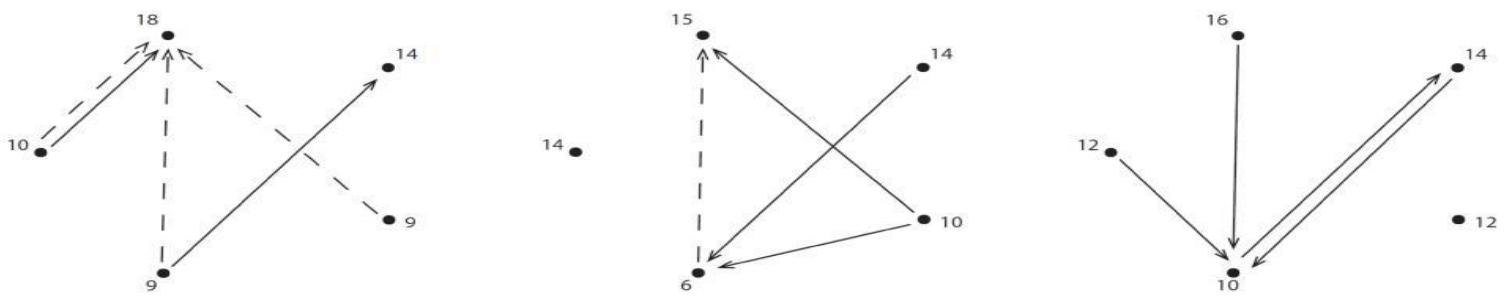

Session 4
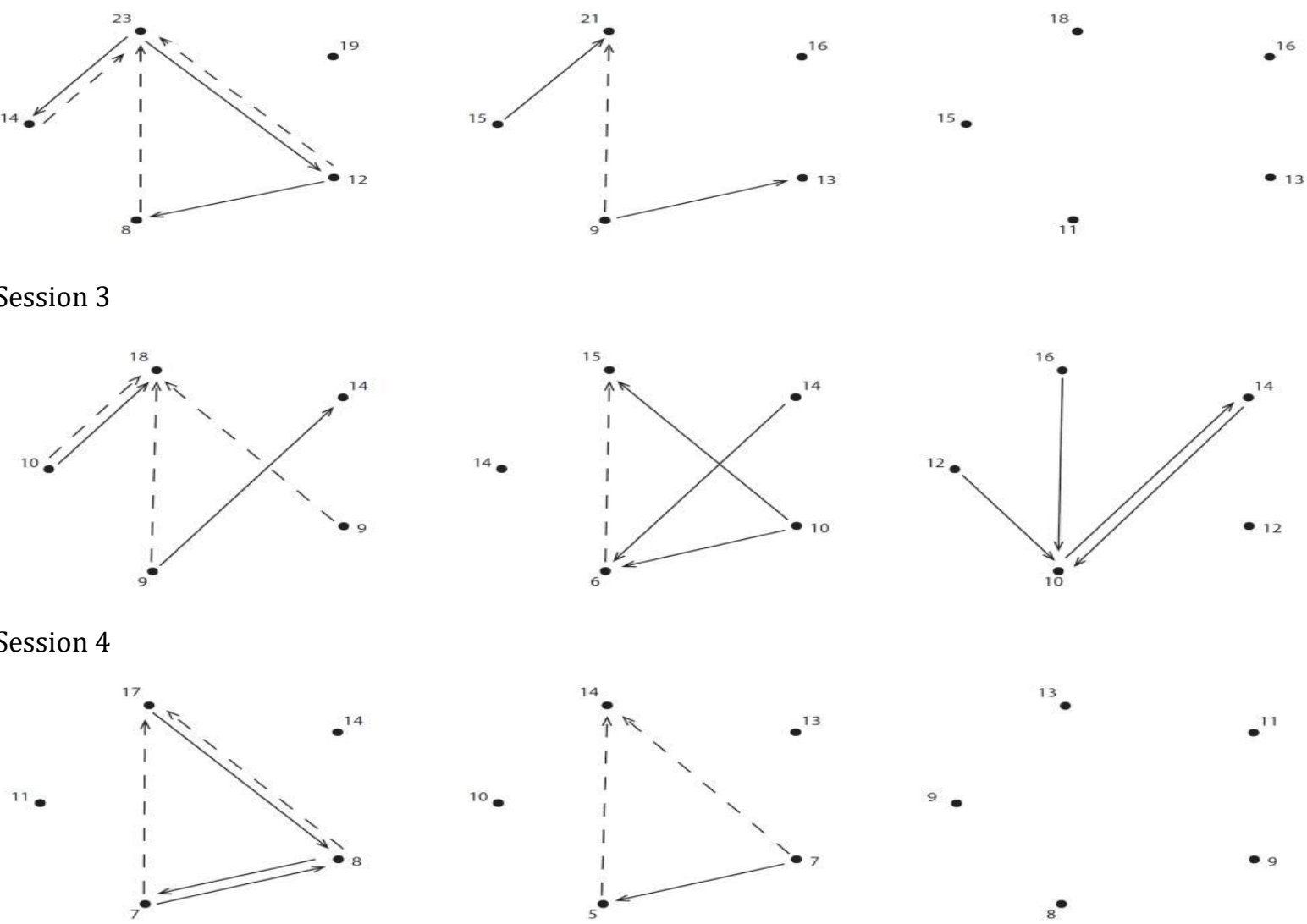

Figure 6: Connections Formed, Distributions

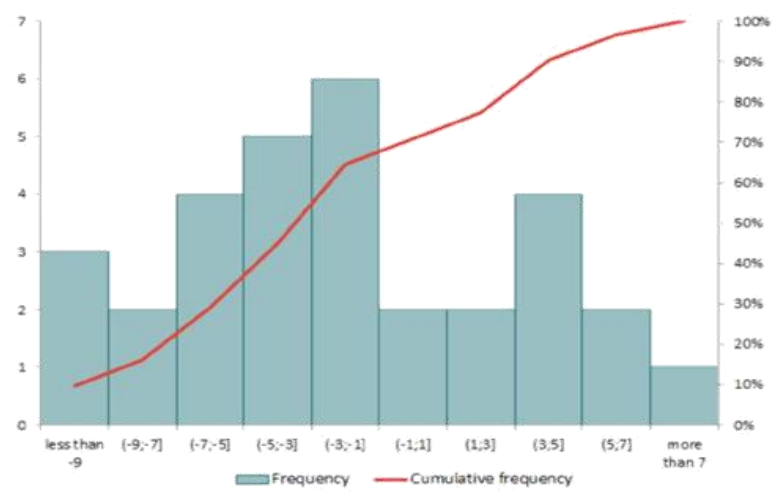

(a) Own - partner's creative ability

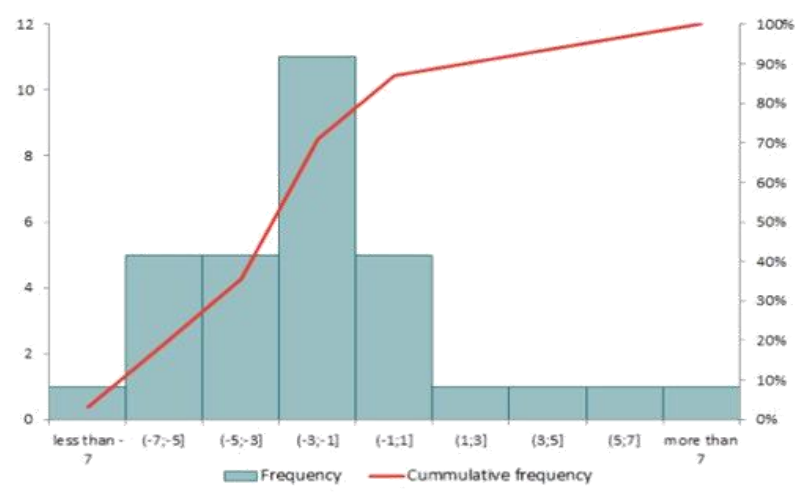

(b) Group's median - partner's creative ability 
Figure 6 characterizes the links formed in the experiment. Figure 6 (a) shows the distribution of differences between own creative ability and the creative ability of the chosen partner. Figure 6 (b) shows the distribution of differences between median creative ability in the participant's group and the partners' creative ability. More than $70 \%$ of all connections are formed to a participant of lower than own creative ability and more than $85 \%$ of the links were formed to a subject of lower than observed median creative ability. Only 2 out of 12 networks formed are optimal and are estimated to have positive net benefits ${ }^{18}$. Two thirds of the networks would lead to net losses according to the estimations presented in Table 3. Defined as a sum of all participants' payoffs (Bala and Goyal, 2000), the efficiency of a network with heterogeneous agents is determined by its structure (Galeotti et al., 2006). Previous experiments conducted to deal with equilibrium network structure and the process of network formation (see for example Callander and Plott, 2005; Berninghaus et al., 2006; Charness et al., 2007; Corbae and Duffy, 2008; Goeree et al., 2009), impose the agents' heterogeneity in costs of forming a link. In this spirit, this paper also deals with structure and efficiency of a network with heterogeneous agents. However, in this real-effort creative environment the costs are determined endogenously and payoffs depend on own effort, ability, investment decisions and uncertain quality of the connections. In line with previous research, the experimental results suggest that whilst some connections are beneficial, the resulting networks are inefficient.

\section{Conclusion and Recommendations}

The experiment described in this paper relies on a simple creative environment that somehow reflects a flow of information between creative professionals. It excludes, however, any communication channel distinct from observing ideas of others. Such synthetic experimental environment does not incorporate opportunities for discussion or feedback, which may be beneficial, in addition to the inspiration derived from observation of output of others. Thus, these experimental results can be considered as a lower bound of potential benefits from creative communication. The first finding of this study is that getting to know ideas of others increases creative productivity of an individual. This implies that availability of information on what others are doing is beneficial for total creative output. The second finding suggests that when this information is costly, the individuals do not extract much use of it. They prefer, in general, save the cost of getting access to this information, by not getting it at all or choose to get it from a cheaper but not so valuable source. These investment decisions in ideas of others are not profit-maximizing in expected terms, and moreover are subject to many behavioral biases, such as overconfidence in own creative ability or attitudes towards risk. As the result, the networks formed by the individuals to exchange creative output are not efficient and deliver less than optimal creative output, on aggregate.

While the first finding is accepted and internalized by firms and organizations, that usually implement policies and practices that facilitate access of ideas for creative professionals (e.g. workshops, regular catchups, online interactions, libraries and other informational resources), the second finding does not seem to be widely recognized despite of some evidence on inefficiencies in R\&D spending (Conte et al., 2009). Learning about what others are doing is almost never for free. Even if the monetary cost associated to this is zero, there is always an opportunity cost of time dedicated to this activity, which is, in case of creative professionals, their most valuable resource. Knowing that individuals prefer not to acquire costly but valuable information and do not invest optimally in getting to know what other do, suggests two complementary policy lines. The first would concentrate on making information acquisition less costly for the professionals. Examples of such policy include minimizing individual's perception of the cost, ideally by directing money flows to more risk neutral organisms rather than individuals (by handling professional subscription decisions on an organization level rather that, letting the professionals decide which of them need to be acquired, reconsidering grant system in academia, by handling it on a department level, rather than on the level of a research group), as well as the effort in actual cost reduction through efficiency improvement of information handling. The second would establish requirements or recommendations for activities dedicated to learning about output of others.

${ }^{18}$ Net benefits for a network are calculated as a total predicted additional output due to connections minus total cost of these connections. 
Examples of this include central planning of the collaborative activities between departments or even organizations, recommendations to dedicate at least 30 minutes a day to browsing a specific online community or studying a specific web resource. Corporate world seems to have incorporated the last action already in their day-to-day activities, for example many consulting firms distribute tailor-made newsletters every morning to their consultants, meaning to serve as information and inspiration source. For the outcomes to be positive, and lead to an increase in aggregate creative output of an organization, all these measures should be carefully evaluated against potential costs and negative impacts they may have in other dimensions. The field of experimental studies on creativity is still developing and many areas remain yet unexplored. Although this study provides evidence on benefits of getting access to ideas of others, it has many limitations, as the experiment was made in one particular creative environment and for one particular creative task. The conclusions, as well as their broader implications, may be not the same for other types of creativity, or reach saturation levels when individuals reach a certain level of information on what others are doing. Another area of future research is the nature of the behavioral effects I observe at an investment stage, as understanding why risk aversion or perceived position matters for connecting behavior would be important for designing policies that overcome these inefficiencies.

\section{References}

Anderson, A. \& Cabral, L. (2007). Go for broke or play it safe? Dynamic competition with choice of variance. RAND Journal of Economics, 38(3), 593-609.

Amabile, T. (1996). Creativity in context, Update to The Social Psychology of Creativity. (Westview Press, Ed.) New York.

Ariely, D., Gneezy, U., Loewenstein, G. \& Mazar, N. (2009). Large Stakes and Big Mistakes. Review of Economic Studies, 76, 451-469.

Bala, V. \& Goyal, S. (2000). A Noncooperative Model of Network Formation. Econometrica, 68(5), 1181-1229.

Berninghaus, S. K., Ehrhart, K. M. \& Ott, M. (2006). A Network Experiment in Continuous Time: The Influence of Link Costs. Experimental Economic, 9, 237-251.

Bradler, C., Neckermann, S. \& Warnke, A. J. (2019). Incentivizing Creativity: A Large-Scale Experiment with Performance Bonuses and Gifts. Journal of Labor Economics, 37(3), 793-851.

Burt, R. S. (2004). Structural Holes and Good Ideas. American Journal of Sociology, 110(2), 349-399.

Byron, K. \& Khazanchi, S. (2012). Rewards and creative performance: A meta-analytic test of theoretically derived hypotheses. Psychological Bulletin, 138(4), 809-830.

Cabral, L. (2003). R\&D Competition When Firms Choose Variance. Journal of Economics \& Management Strategy, 12(1), 139-150.

Callander, S. \& Plott, C. R. (2005). Principles of Network Development and Evolution: An Experimental Study. Journal of Public Economics, 89, 1469-1465.

Charness, G. \& Grieco, D. (2019). Creativity and Incentives. Journal of the European Economic Association, 17(2), 454-496.

Charness, G., Corominas-Bosch, M. \& Frechette, G. R. (2007). Bargaining and Network Structure: An experiment. Journal of Economic Theory, 136, 28-65.

Christensen, P. R., Guilford, J. P. \& Wilson, R. C. (1957). Relations of Creative Responses to Working Time and Instructions. Journal of Experimental Psychology, 53(2), 82-88.

Collins, M. A. \& Amabile, T. M. (1999). Motivation and Creativity. In R. J. Sternberg (Ed.), Handbook of Creativity (pp. 297-312). Cambridge, England: Cambridge University Press.

Conte, A., Schweizer, P., Dierx, A. \& Ilzkovitz, F. (2009). An Analysis of the Efficiency of Public Spending and National Policies in the Area of R\&D. European Economy Occasional Papers.

Corbae, D. \& Duffy, J. (2008). Experiments with Network Formation. Games and Economic Behavior, 64, 81120.

Cross, R., Hargadon, A., Parise, S. \& Thomas, R. (2008). Critical Connections: Driving Innovation With A Network Perspective. Sloan Management Review and Wall Street Journal Weekend Edition.

Ductor, L., Fafchamps, M., Goyal, S. \& van der Leij, M. (2014). Social networks and research output. Review of Economics and Statistics.

Dugosh, K. L., Paulus, P. B., Roland, E. J. \& Yang, H. C. (2000). Cognitive Stimulation in Brainstorming. Journal of Personality and Social Psychology, 79, 722-735. 
Eisenberg, R. \& Rhoades, L. (2001). Incremental effects of Reward on Creativity. Journal of Personality and Social Psychology, 81, 728-741.

Fischbacher, U. (2007). z-Tree: Zurich Toolbox for Ready-made Economic Experiments. Experimental Economics, 10(2), 171-178.

Galenson, D. (2004). A Portrait of the Artist as a Very Young or Very Old Innovator: Creativity at the Extremes of the Life Cycle. NBER Working Paper No. 10213.

Galeotti, A., Goyal, S. \& Kamphorst, J. (2006). Network Formation with Heterogeneous Players. Games and Economic Behavior, 54, 353-372.

Gneezy, U. \& Rustichini, A. (2000). Pay Enough or Don't Pay at All. Quarterly Journal of Economics, 115, 791810.

Goyal, S., van der Leij, M. J. \& Moraga-Gonzalez, J. L. (2006). Economics: An emerging small world. Journal of Political Economy, 114(2), 403-412.

Goeree, J. K., Riedl, A. \& Ule, A. (2009). In Search of Stars: Network Formation among Heteroheneous Agents. Games and Economic Behavior, 67, 445-466.

Gross, D. P. (2018). Creativity Under Fire: The Effects of Competition on Creative Production. SSRN 2520123.

Guilford, J. P. (1950). Creativity. American Psychologist, 5, 444-454.

Guilford, J. P. (1967). The Nature of Human Intelligence. New York: McGraw-Hill.

Hey, J. D. \& Orme, C. (1994). Investigating Generalizations of Expected Utility Theory Using Experimental Data. Econometrica, 62(6), 1291-1326.

Heckman, J. (1979). Sample selection bias as a specification error. Econometrica, 47(1), 153-161.

Hennessey, B. A. \& Amabile, T. M. (1998). Reward, Intrinsic Motivation, and Creativity. American Psychologist, $53,674-675$.

Hoelzl, E. \& Rustichini, A. (2005). Overconfident: Do You Put Money On It? The Economic Journal, 115, 305318.

Kachelmeier, S. J., Reichert, B. E. \& Williamson, M. G. (2008). Measuring and Motivating Quantity, Creativity, or Both. Journal of Accounting Research, 46.

Kahneman, D. (2011). Thinking, Fast and Slow. New York: Farrar, Straus and Giroux.

Kim, K. (2006). Can we trust creativity tests? A review of the Torrance Tests of Creative Thinking (TTCT). Creativity Research Journal, 18(1), 3-14.

Kohn, A. (1993). Punished by Rewards. Boston: Houghton Mifflin.

Manski, C. F. (1993). Identification of endogenous social effects: The reflection problem. Review of Economic Studies, 60(3), 531-542.

Meusburger, P. (2009). Milieus of Creativity: The Role of Places, Environments and Spatial Contexts. In P. Meusburger, J. Funke, \& E. Wunder (Eds.), Milieus of Creativity: An Interdisciplinary Approach to Spatiality of Creativity. Springer.

Moffitt, R. A. (2001). Policy interventions, low-level equilibria, and social inter-actions. In S. Durlauf, \& P. Young (Eds.), Social Dynamics. Cambridge, MA: MIT Press.

Mumford, M. D. (2003). Where have we been, where are we going? Taking stock in creativity research. Creativity Research Journal, 15, 107-120.

Nickerson, R. S. (1999). Enhancing Creativity. In Handbook of Creativity.

Nielsen, B. D. \& Simonton, D. K. (2008). Conceptual versus Experimental Creativity: Which Works Best on Convergent and Divergent Thinking Tasks? Psychology of Aesthetics, Creativity, and the Arts, 2, 131138.

Nijstad, B. A. \& Stroebe, W. (2006). How the Group Affects the Mind: A Cognitive Model of Idea Generation in Groups. Personality and Social Psychology Review, 10(3), 186-213.

Nijstad, B. A., Stroebe, W. \& Lodewijkx, H. F. (2002). Cognitive Stimulation and Inference in Groups: Exposure Effects in an Idea Generation Task. Journal of Experimental Social Psychology, 38, 535-544.

Paulus, P. B. \& Yang, H. C. (2000). Idea Generation in Groups: A Basis for Creativity in Organizations. Organizational Behavior and Human Decision Process, 82, 76-87.

Runco, M. A. (2006). Creativity: Theories and Themes: Research, Development, and Practice. San Diego: Academic Press.

Runco, M. A. (2007). Correcting the Research on Creativity. Creativity Research Journal, 17, 321-327.

Rutstrom, E. E. \& Williams, M. B. (2000). Entitlements and Fairness: An Experimental Study of Distributive Preferences. Journal of Economic Behavior \& Organization, 43, 75-89. 
Shalley, C. \& Perry-Smith, J. (2001). Effects of social-psychological factors on creative performance: The role of informational and controlling expected evaluation and modeling experience. Organizational Behavior and Human Decision Processes, 84, 1-22.

Stanovich, K. \& West, R. (2000). Individual Difference in Reasoning: Implications for the Rationality Debate? Behavioural and Brain Sciences, 23, 645-726.

Stein, M. I. (1974). Stimulating Creativity. New York: Academic Press.

Sternberg, R. J. (2006). The Nature of Creativity. Creativity Research Journal, 18(1), 87-98.

Stroebe, W. \& Diehl, M. (1994). Why Groups Are Less Effective than Their Members: On Productivity Losses in Idea-Generating Groups. European Review of Social Psycholigy, 5, 271-303.

Torrance, E. P. (1974). Torrance Tests of Creative Thinking. Scholastic Testing Service, Inc.

Treffinger, D. J., Isaksen, S. G. \& Dorval, K. B. (2006). Creative Problem Solving: An Introduction. Waco, TX: Prufrock.

Woodman, R. W., Sawyer, J. I. \& Griffin, R. W. (1993). Toward a Theory of Organizational Creativity. Academy of Management Review, 18, 293-321.

\section{Appendix}

Instructions: Graphic Task: The purpose of this experiment is to study the behavior on decision-making. Do not think that any particular behavior is expected from you. However, be aware that your decisions will affect the money you can earn during the experiment. These instructions will explain you the rules of the experiment. Instructions are identical for all participants. The anonymity of the participants and their decisions is also guaranteed. Please, it is important that you do not talk to nor disturb other participants. If you need help, raise your hand and wait in silence. Someone will come to you as soon as possible. This experiment consists of two Stages (and each stage consists of 3 phases). Your total earnings in the experiment will be determined at the end of it, as a sum of three phases of a randomly chosen stage.

\section{Stage 1}

Phase 1: All the tasks of this phase have to be done with BLUE color pen, which you already have on your table. Phase 1 begins once we finish reading instructions and will last 6 minutes. In this phase you will get a sheet of paper containing cells with geometric forms, which you would need to complete to get a drawing of a concrete object (precise, definite). Each drawing has to stay inside of a cell. A drawing can be very schematic, the quality of the drawing doesn't have any importance, but it has to be clear which object are you referring to. You are free to rotate the form and skip some cells

Figure 1

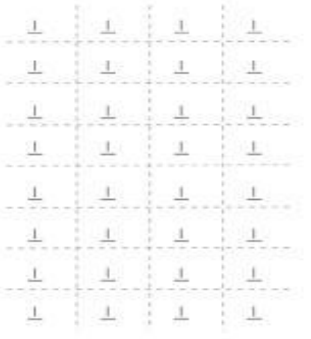

Figure 2

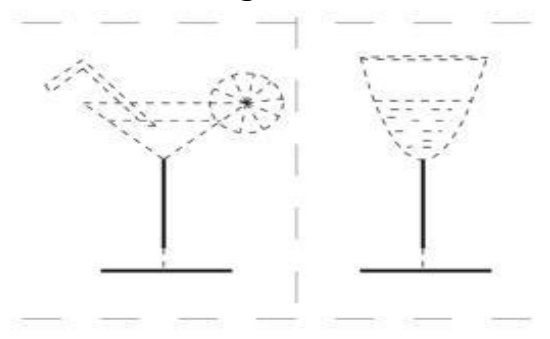

Figure 3

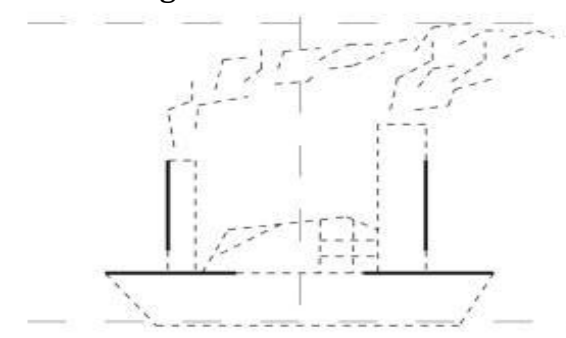

Your earnings in this phase will be determined as follows. For each unique drawing you will receive 50 cents. So, to earn more money, you task is to make as much different drawings as possible. Figure 1 contains an example of the sheet you will receive. In this example each drawing should contain just one of the inverses Ts. Figure 2 shows two examples of drawings with this form. Given that both use inverse $\mathrm{T}$ as a base for the glass, these two drawings cannot be considered as conceptually different. In this case the participant will receive just 50 cents as for one drawing. Figure 3 gives an example of a drawing using two geometric forms. This drawing intersects the boundary of the cell, which is prohibited by the rules. In this case the participant will receive 0 cents for the drawing of a boat. Summarizing, the total amount of money you can get in this phase depends on the number of conceptually unique drawings that you do. 
Phase 2: All the tasks of this phase have to be done with BLACK color pen, which you already have on your table. Phase 2 starts after reading the instructions and will last 2 minutes. In this phase we will give you an example of a drawing which you haven't done in the previous phase and which incorporates given geometric form. This example is just for you, it is important not to show it to any other participant and not to try to see the examples of others. To assure that you receive a NEW example, please, if the envelope contains the drawing that you already have, raise your hand and we will give you another drawing. After receiving an example, your task is to continue drawing as much drawings as you can, that contain given geometric form. Use the same sheet of paper we gave you at the beginning of the experiment. The requirements are the same as in the previous phase: each drawing has to be inside of a cell, can be very schematic, the quality doesn't matter, but has to be understandable which object you are referring to. It's OK to skip some cells. It's not OK to draw the same example we gave you. Your earnings in this phase have the same structure as the previous one: for each unique drawing you can receive 50 cents. So, the total earnings in this phase depend just on the number of unique drawings you produce in these 2 minutes.

\section{Stage 2}

Phase 2 (see Stage 1 for Phase 1): All the tasks of this phase have to be done with BLACK color pen, which you already have on your table. Phase 2 starts after reading the instructions and will last 2 minutes. In this phase you can BUY an example of a drawing which you haven't done in the previous phase and which uses given geometric form. The price is _ EUR. This example would be just for you, it is important not to show it to any other participant and not to try to see the examples of others. To assure that you receive a NEW example, please, if the envelope contains the drawing that you already did, raise your hand and we will give you another drawing. After receiving the example, your task is to continue drawing as much drawings as you can, that contain given geometric form. Use the same sheet of paper we gave you at the beginning of the experiment. The requirements are the same as in the previous phase: each drawing has to be inside of a cell, can be very schematic, the quality doesn't matter, but has to be understandable which object you are referring to. It's OK to skip some cells. It's not OK to draw the same example we gave you.

Figure 7: Examples Suggested to the Participants ${ }^{19}$.
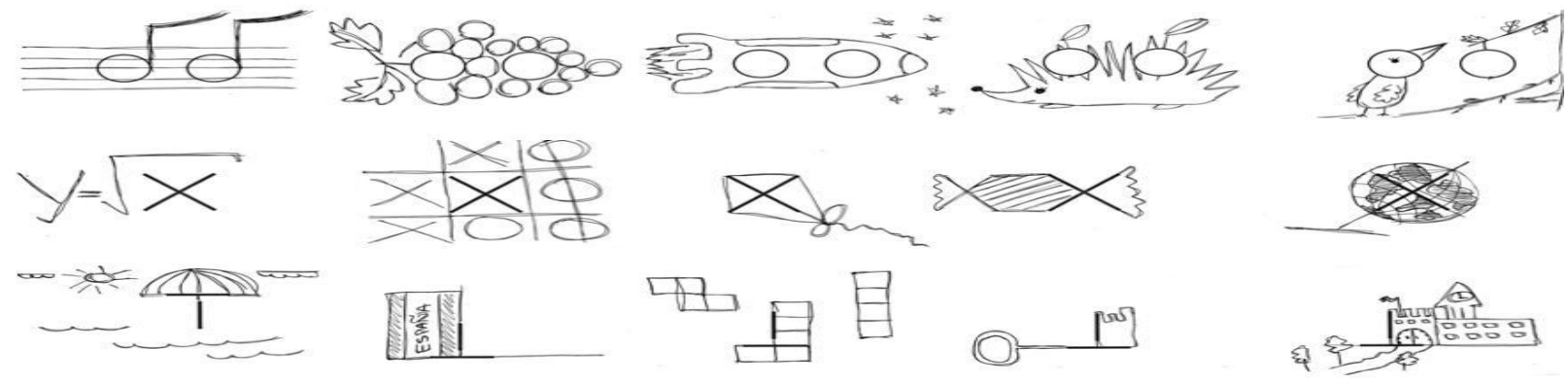

Instructions: Verbal Task: The purpose of this experiment is to study the behavior on decision-making. Do not think that any particular behavior is expected from you. However, be aware that your decisions will affect the money you can earn during the experiment. These instructions will explain you the rules of the experiment. Instructions are identical for all participants. The anonymity of the participants and their decisions is also guaranteed. Please, it is important that you do not talk to nor disturb other participants. If you need help, raise your hand and wait in silence. Someone will come to you as soon as possible. This experiment consists of two Stages. Your total earnings in the experiment will be determined at the end of it, as a sum of three phases of a randomly chosen stage. Your earnings in this phase have the following structure: for each unique drawing you can receive 50 cents minus the total investments cost (if occurred). So, the total

\footnotetext{
${ }^{19}$ Not part of instructions. The examples were suggested in the presented order for each geometric form. In case the individual already had the example proposed, the next by order was suggested and so on. Never more than one change was needed, one change was needed in 4 cases.
} 
earnings in this phase depend on the number of unique drawings you produce in these 2 minutes AND your investment decision.

Stage 1: At the beginning of this Stage you will be shown a well-known and widely used object. Your task will be to find various ways to use this object different from the usual one. For example, the usual use of a book is to read it and one possible unusual use would be to use it as a carpet for computer mouse. This phase will last 10 minutes and for each conceptually different unusual use you will receive 50 cents. It is very important not to introduce similar uses, because for each similar use you suggest we will substract 50 cents from your earnings. For example, if you have said that a book can be used to keep the door open, you will receive 50 cents for this idea, but if you add 'to keep the window open', 50 cents will be substracted from your earnings and in total you would receive zero for these two uses because they are not conceptually different. To summarize, to earn more money your task is to produce as many different unusual uses as possible. How to use the computer in this task: To let us know the uses you come up with, you will use the computer. To introduce a use you need to type it in the bottom part of the screen - as it is shown on the picture below - and then press 'ENTER' button. Please, enter each new use in a new line. In this way, the will be numerated automatically. In the left top corner of the screen you will see the statistics on the total numbers of uses you have already suggested and your earnings so far.

Figure 1

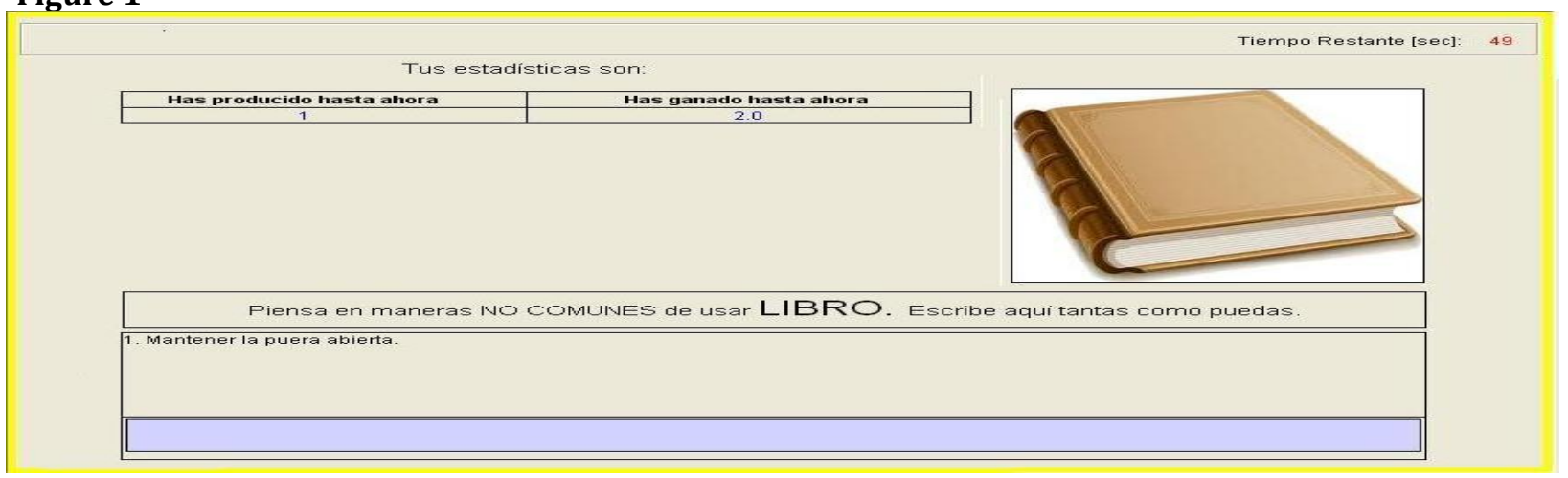

Important: in case you make entries with no sense, irrelevant or just enter empty lines, the computer will not recognize the error immediately and will increase your earnings. However, this will be checked upon termination of the experiment, and if such a behavior is detected, all the earnings in a corresponding phase will be cancelled. After first 6 minutes of the task you will have a little break, and after it you will continue with the same task, the same object and the same rules. The screen will show you all ideas that a random person in this room came up with. Observing the ideas of others can help you to generate more your own ideas, however, you should not copy the ideas of others or introduces similar, because in this case it will not be a different use anymore and 50 cents will be substracted from your earnings.

Stage 2: At the beginning of this Stage you will be shown ANOTHER well-known and widely used object. As in the previous stage, your task will be to find various ways to use this object distinct from the usual one. As in the previous stage you should enter your ideas in the bottom part of the screen. The stage will last 10 minutes and for each conceptually different unusual use you will be paid 50 cents. As in the previous stage, after first 6 minutes you will have a little break and after it you will need to continue with the same task, the same object and the same rules. This time, you and 4 other people in this room chosen randomly will form a group, which composition will remain constant until the end of the session. In addition to your statistics you will see a table containing the number of ideas each member of your group has, like this: 


\section{Figure 2}

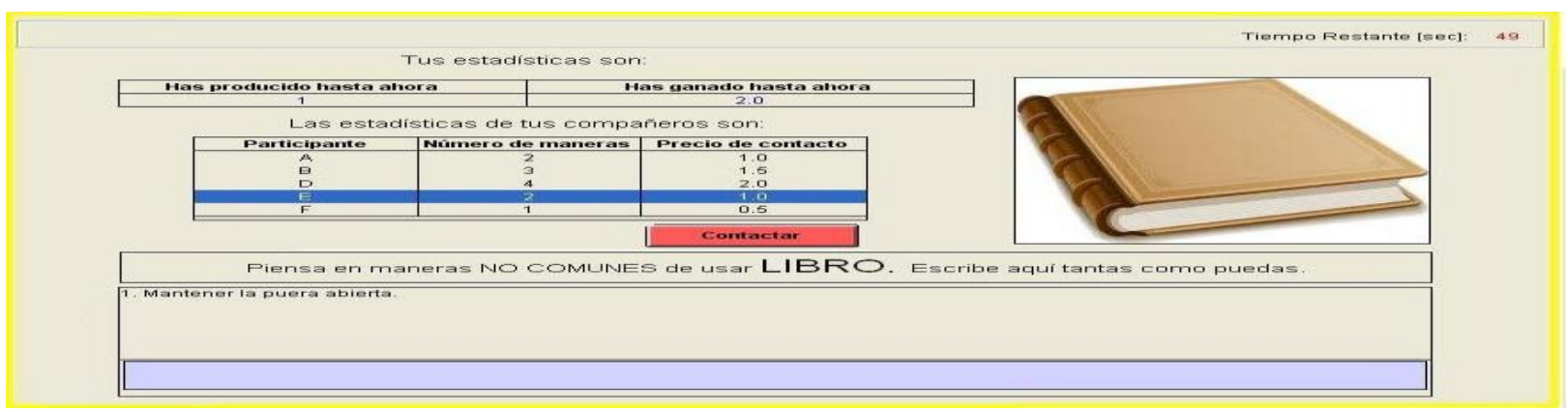

To each one of you the 'contact price' will be assigned, which is proportional to the total number of unusual uses the member suggested. The greater is the output - the more expensive will be to contact a particular member. You will also see these prices in the statistics table. When you want, you can see the unusual uses suggested by a member of your group paying the price of contact to do so, please, select corresponding line and press the button 'CONTACT'. The screen will show you all the ideas of the selected person in the middle. You can choose to contact one person only, multiple persons or not to make contacts at all. Total amount of money spent making contacts by you will be shown in the table of your statistics. To be able to contact someone, you have to have sufficient earnings, in case you don't - the error message will appear. Important: in case you make entries with no sense, irrelevant or just enter empty lines, the computer will not recognize the error immediately and will increase your earnings. However, this will be checked upon termination of the experiment, and if such a behavior is detected, all the earnings in a corresponding phase will be cancelled.

\section{Risk-Elicitation}

Instructions: In each of the 24 rounds of this phase, we present you two lotteries and you will have to choose the one you prefer. At the end of the experiment the server will determine randomly one out of the 24 rounds, and you will be paid the money that results from playing the lottery you selected. In each round, there will appear two lotteries on your screen. You will have to choose one. Each lottery assigns different probabilities to win four prizes of $0,5,10$ and 15 euros, respectively. Each prize is associated with one color. This association between prizes and colors will hold for all 24 rounds in this phase. The figure below shows an example of a lottery.

\section{Figure 3}

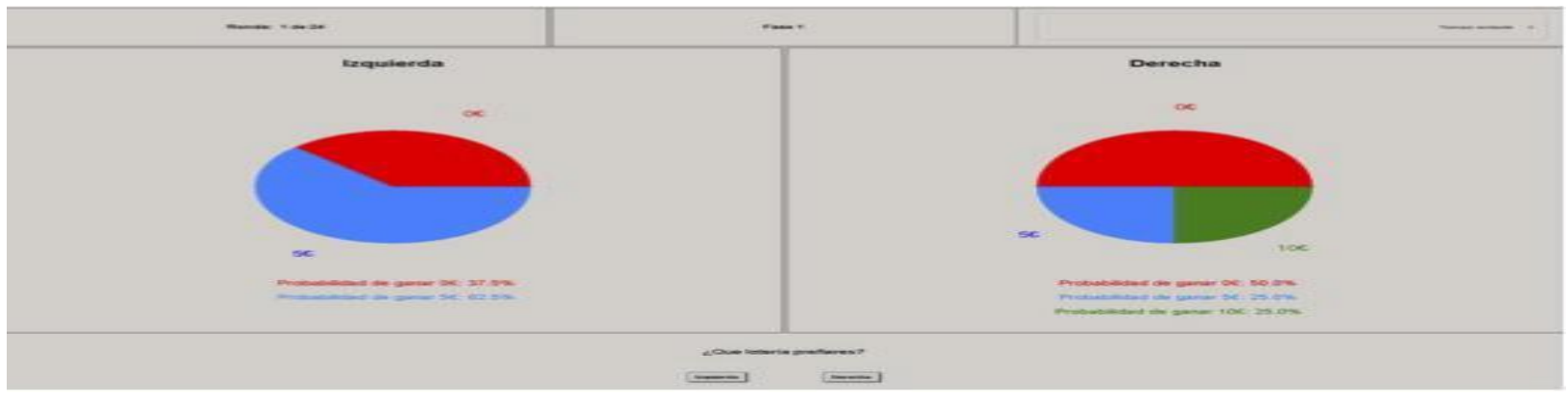

If you choose the lottery on the LEFT, you can earn 0 euros with a probability of $37.5 \%$ or 5 euros with a probability of $62.5 \%$. If, on the contrary, you choose the lottery on the RIGHT, you can earn 0 with a probability of 50\%, 5 euros with a probability of $25 \%$ and 10 euros with a probability of $25 \%$. In each round, you simply have to choose the lottery you prefer by clicking on the corresponding button. It is important that you play all 24 lotteries as if it was the one determining your payoff. This is due to the fact that after the experiment the server will choose one out of the 24 rounds, and will play the lottery chosen by you in that round. In summary, the money you earn depends on the round chosen randomly by the server and the result of the lottery chosen by you in that round. 


\section{Journal of Economics and Behavioral Studies (ISSN: 2220-6140)}

Vol. 11, No. 5, pp. 20-44, October 2019

Estimation: The risk aversion parameter is estimated for each individual separately by Maximum Likelihood estimation procedure. For this purpose, an Expected Utility specification is used:

$$
E U_{i}=\sum_{m=1}^{4}\left[q_{m} \times u\left(w_{m}\right)\right]
$$

$q_{m}$ and $w_{m}$ are the probabilities and prizes in each lottery.

Denote the utility function

$u(x)=x^{\rho}$

Based on latent preferences and choosing a logistic CDF, the conditional log-Likelihood Function is:

$$
\ln L(\rho, c)=\sum_{1}\left[\ln \left(\left.\frac{\exp \left(E U_{L}\right)}{\sum_{c}=L, \operatorname{Rexp}\left(E U_{c}\right)}\right|_{c=L}\right)+\ln \left(\frac{\exp \left(E U_{R}\right)}{\sum_{c}=L, \operatorname{Rexp}\left(E U_{c}\right)} l_{c=R}\right)\right]
$$

The estimated $\rho$ parameters vary substantially across individuals. The average estimate is 0.64 and the standard deviation is 0.33 .

\section{Self-Assessment}

Instructions: In Verbal task all the participants assessed their own creative ability with respect to performance of others. Between stage 1 and stage 2 of phase I, the individuals were given feedback on their output and were asked to guess how many participants in their session have come up with more items than themselves. Figure 4 shows a screenshot of this task.

\section{Figure 4: Overconfidence Task}

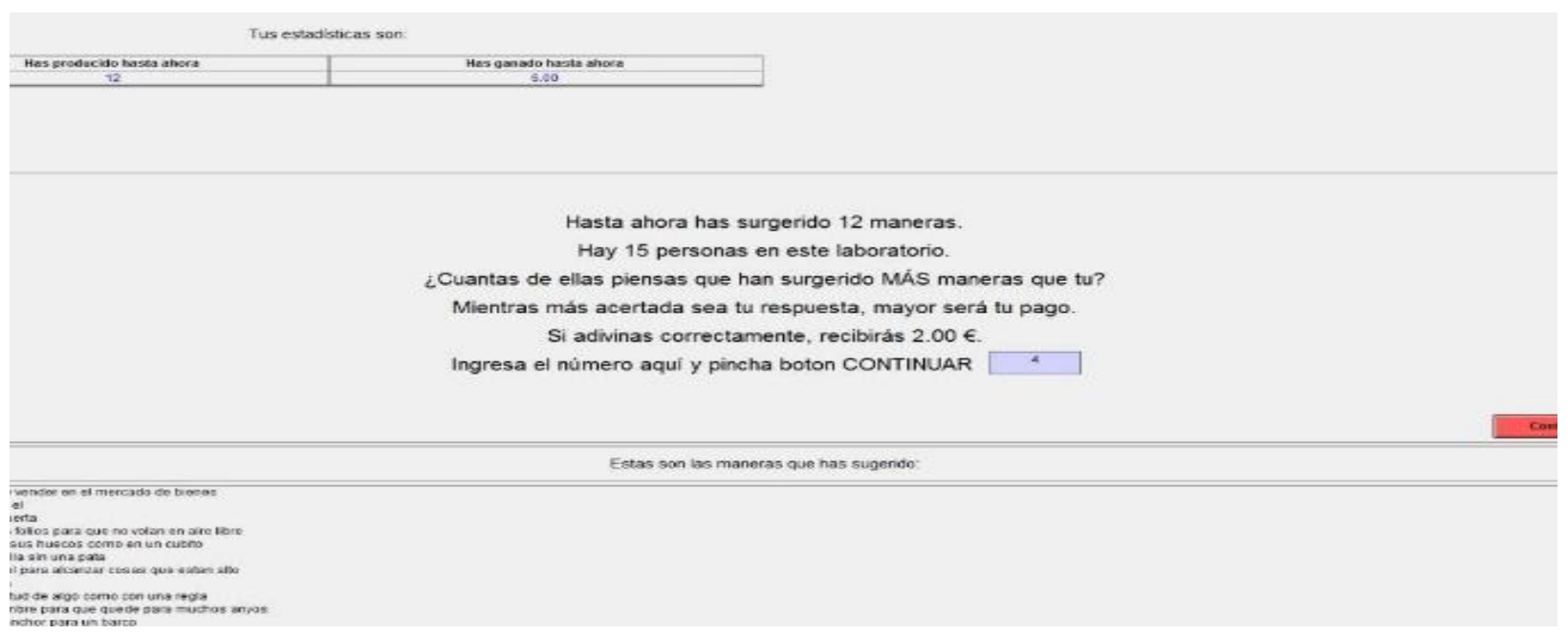

Quadratic scoring rule was used as an incentive scheme: the participants who have guesses correctly received 1.5 euros, and the less precise was the guess, the less money was paid.

Estimation: The self-confidence parameter used in estimations is calculated as the self-identified position normalized over number the participants in a session. For example, if a subject said that there are 4 participants with more items than herself, her self-confidence parameter would be 20 (her ranking in ascending order) over 24 (total number of participants in the session, resulting in 0.83 . 